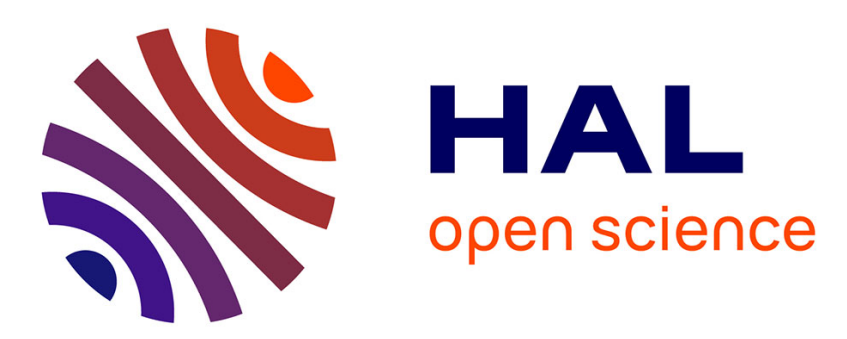

\title{
Parameterization of the urban energy budget with the submesoscale soil model
}

\author{
Sylvain Dupont, Patrice Mestayer
}

\section{To cite this version:}

Sylvain Dupont, Patrice Mestayer. Parameterization of the urban energy budget with the submesoscale soil model. Journal of Applied Meteorology and Climatology, 2006, 45 (12), pp.1744-1765. 10.1175/JAM2417.1 . hal-02666518

\section{HAL Id: hal-02666518 https://hal.inrae.fr/hal-02666518}

Submitted on 31 May 2020

HAL is a multi-disciplinary open access archive for the deposit and dissemination of scientific research documents, whether they are published or not. The documents may come from teaching and research institutions in France or abroad, or from public or private research centers.
L'archive ouverte pluridisciplinaire HAL, est destinée au dépôt et à la diffusion de documents scientifiques de niveau recherche, publiés ou non, émanant des établissements d'enseignement et de recherche français ou étrangers, des laboratoires publics ou privés. 


\title{
Parameterization of the Urban Energy Budget with the Submesoscale Soil Model
}

\author{
SYLVAIN DUPONT \\ INRA-EPHYSE, Villenave d'Ornon, France \\ PAtrice G. Mestayer \\ Laboratoire de Mécanique des Fluides, UMR CNRS 6598, Ecole Centrale de Nantes, Nantes, France
}

(Manuscript received 16 November 2005, in final form 22 March 2006)

\begin{abstract}
The thermal component of the Soil Model for Submesoscales, Urbanized Version (SM2-U), is described. SM2-U is an extension on a physical basis of the rural Interactions between Soil, Biosphere, and Atmosphere (ISBA) soil model to urban areas. It evaluates the turbulent energy, moisture, and radiative fluxes at the urban canopy-atmosphere interface to provide lower boundary conditions of high-resolution mesoscale models. Unlike previous urban canopy schemes, SM2-U integrates in a simple way the physical processes inside the urban canopy: the building wall influence is integrated in the pavement temperature equation, allowing the model to compute directly the energy budget of street canyons. The SM2-U model is evaluated on the Marseille, France, city-center energy-budget components measured during the field experiments to constrain models of atmospheric pollution and transport of emissions [Expérience sur Site pour Contraindre les Modèles de Pollution Atmosphérique et de Transport d'Emissions (ESCOMPTE)] urban boundary layer (UBL) campaign (June-July 2001). The observed behavior of net radiation and heat fluxes is reproduced by SM2-U with a high level of quality, demonstrating that the influence of building walls may be well modeled by modifying the pavement temperature equation. A sensitivity analysis shows that the accurate account of wall area and the parameterization of both the fast response of artificial materials to environmental forcing variations and their heat storage capacity are essential for mesoscale simulations of the urban boundary layer; they are probably more important than accurate but complex computation of radiative trapping (effective albedo and emissivity)
\end{abstract}

\section{Introduction}

In the last few years, several models improved the urban canopy parameterization in simulation of the urban climatology, urban heat island, and, indirectly, urban air quality. A traditional approach in mesoscale simulations with atmospheric models, including a vegetation/soil model, consists of considering urban areas as a type of bare soil with adapted values of the soil parameters (albedo, heat capacity, etc.). Recent developments of this approach include improvements of the parameters for this soil type. Best (2005) developed a simple urban parameterization in operational numerical weather prediction models at a resolution of about $12 \mathrm{~km}$, where urban surfaces are essentially represented as a canopy of concrete. Rotach (1999) stressed the

Corresponding author address: Sylvain Dupont, INRAEPHYSE, BP 81, 33883 Villenave d'Ornon, France.

E-mail: sdupont@bordeaux.inra.fr influence of roughness length parameterization, while De Ridder and Schayes (1997) focused on the thermal roughness length influence. The Local-Scale Urban Meteorological Preprocessing Scheme model of Grimmond and Oke (2002) computes the energy budget with semiempirical parameterizations, including the Objective Hysteresis Model (Grimmond and Oke 1999). This empirical correlation between the heat storage in the urban fabric, net radiation, and urban land cover fractions is based on measurements over a dozen of American cities; it allows for the introduction of the phase lag between fluxes resulting from the heat storage in urban materials. Specific urban canopy models have also been developed on a mechanistic basis (Masson 2000; Kusaka et al. 2001; Ca et al. 2002; Martilli et al. 2002; Dupont et al. 2004; Otte et al. 2004). Except for Dupont et al. (2004) and Ca et al. (2002), these models are exclusively urban, fitted to the structure of regular dense city centers and ignoring the sparse vegetation and empty areas; for simulating large areas they must 
therefore be associated with a rural soil model to compute the transfers at natural surfaces. A tiling approach is then used to represent the heterogeneity of real urban areas, with the disadvantage that the two schemes (urban and rural) do not exchange with each other at the subgrid scale. Using two incompatible schemes, an urban one for the "paved city" and a rural one for the "vegetated city," does not seem a good approach when studying the urban microclimatology because in most districts vegetation, pavement, and buildings are intermixed. The tiling approach emphasizes the vertical transfers and skips the interactions between the different cover modes, such as dispersed vegetation interspersed between buildings or in streets and squares. In the multilayer models of Martilli et al. (2002), Ca et al. (2002), Otte et al. (2004), and Dupont et al. (2004), the first few grid mesh layers are within the canopy layer and the momentum, heat, and turbulence kinetic energy equations are modified to include building source/ sink terms. For these models, the calculation of heat fluxes is required at several levels within the canopy. With the single layer models of Masson (2000) and Kusaka et al. (2001), the roughness approach is used and the integrated influence of the whole canopy is modeled. These models are essentially designed to provide the canopy heat fluxes for the lower boundary condition of atmospheric mesoscale models. To save the computational time and to keep reasonable the number of model-dependent parameters, the singlelayer models need to be as simple as possible while treating accurately the key processes. In the Town Energy Budget (TEB; Masson 2000) model, the urban canopy is assumed to be an isotropic array of street canyons composed of three types of surfaces (roof, wall, and road), where the heat transfers are computed through several layers of materials, generally four. The street heat fluxes and radiation budgets are obtained by computing wall and road energy separately, including the radiation multiple reflections within the streets. In these detailed budgets the heat exchange coefficients between the surfaces and the air inside the canopy, and between the canopy and the air above, and the wind speed inside the canopy are computed using empirical parameterizations that contain large uncertainties.

The resolution of urban surfaces for computing surface energy fluxes by atmospheric models depends on the desired resolution of meteorological fields. For example, a detailed resolution of urban surfaces may not be required for weather prediction systems, a global effect being sufficient, whereas it is required for local air quality prediction as explained by Dupont et al. (2004). In the current article, the Soil Model for Submesoscales, Urbanized Version (SM2-U), and its evalu- ation against measurements obtained at the Marseille, France, city center are presented. This model has been developed for providing the input data at the lower boundary of atmospheric mesoscale models for simulations at very fine spatial resolution (less than a kilometer) under all meteorological conditions (Guilloteau 1999; Dupont 2001). It is used for studies of urban micrometeorology and microclimatology as well as for high-resolution air quality simulations (Dupont et al. 2004). It has been implemented with numerical weather prediction models such as the fifth-generation Pennsylvania State University-National Center for Atmospheric Research Mesoscale Model (MM5; Dupont et al. 2004), the Advanced Regional Prediction System (Dupont et al. 2002), and the High-Resolution Limited Area Model (Mahura et al. 2004). Starting from Pleim and Xiu's (1995) version of the "force-restore" rural soil model of Noilhan and Planton (1989), later known as the Interaction between Soil, Biosphere, and Atmosphere model (ISBA; Noilhan and Mahfouf 1996), SM2-U was developed on physical bases to extend ISBA by including the urban surfaces such as road systems, housings in low and high densities, and dense continuous urban canopies.

The first advantage of SM2-U, over previous urban soil models, is that it models in a unique code all of the soils encountered in an urban area from the rural outskirts to the city centers, with any distribution of surface cover fractions, keeping all of the schemes for the natural soils with vegetation that were extensively validated in the various comparisons of ISBA with experimental data (e.g., Giordani et al. 1996). SM2-U includes a onelayer urban-and-vegetation canopy model to integrate the physical processes inside the urban canopy and three soil layers as introduced by Boone et al. (1999) in the latest version of ISBA. Because SM2-U is used at high resolution where vegetated ground, pavement, and buildings are often intermixed in each computational cell, the two lower soil layers extend under all surface types of a grid cell. Therefore, the model combines the tiling and integrated approaches. The tiling approach is used for computing grid fluxes as the sum of the individual patch fluxes, while the integrated approach is used through the unique overlying atmosphere and underlying soil layers. Subgrid-scale interactions between impervious and natural surfaces appear directly in surface water runoffs (see Dupont et al. 2006) and indirectly through the evapotranspiration and heat fluxes from the common soil water content and air temperature and humidity of the atmosphere of the surface grid cell. For example, a grid box containing a large density of impervious surfaces connected to the drainage network is likely to be an area where vegetation does suf- 
fer from the reduction of soil moisture because it is drained under the impervious surfaces.

The second difference is that physical processes inside the urban canopy, such as heat exchanges, heat storage, radiative trapping, water interception, or surface water runoff, are integrated in a simple way. Unlike other detailed urban soil models, SM2-U solves directly the heat fluxes from the street canyons by integrating the building walls and the paved surfaces into a unique energy budget, with neither separated walls and roads energy budgets nor wind speed parameterization inside the canopy. The building wall influence is threefold in this budget: the additional flux of heat stored in building materials; a modified heat capacity, including wall capacity; parameterized effective albedo; and emissivities accounting for the radiative trapping.

The model hydrological part (water budgets and latent heat fluxes) has been presented in a companion paper (Dupont et al. 2006) where it is validated on a suburban district at rainy event and annual scales. The present article focuses on the thermal component of SM2-U and its validation over the downtown core of Marseille against measurements of Grimmond et al. (2004) recorded during the 2001 field experiment to constrain models of atmospheric pollution and transport of emissions [Expérience sur Site pour Contraindre les Modèles de Pollution Atmosphérique et de Transport d'Emissions (ESCOMPTE); Cros et al. 2004] urban boundary layer campaign (UBL-ESCOMPTE; Mestayer et al. 2005). The model is presented in section 2. Marseille measurements and simulations are first presented and the simulated fluxes are compared with measurements in section 3. The energy budget is analyzed in section 4 , including a sensitivity study that stresses the influence of building wall parameterization in the energy budget diurnal cycle.

\section{The SM2-U soil model}

\section{a. Model presentation}

SM2-U extends the force-restore model of Noilhan and Planton (1989) to the urban areas, keeping the roughness approach where the surface stress is represented by means of a roughness length and a displacement height. The only horizontal exchanges inside the urban canopy are radiation reflections and water runoff from saturated surfaces, while the subgrid-scale transfers in the soil are ensured by water and heat redistribution in the root-influenced and deep soil layers. The wind advection within the canopy layer is not considered.

While for a natural soil partly covered with vegetation ISBA computes the budgets for the whole ground- vegetation system, in each computational cell SM2-U separates the following eight surface types (Fig. 1): for natural grounds, the bare soil without vegetation on a large area, noted "bare," and for vegetated areas the soil located between vegetation elements "nat" (e.g., gaps within a lawn) and the vegetation cover "vegn"; for anthropized areas, the building roofs "roof," the bare paved surfaces (without vegetation) "pav," the vegetation elements over a paved surface (e.g., roadside trees) "vega," and the paved surface under the vegetation (e.g., pavements under tree crown) "cova"- this latter surface type is only used for the computation of the surface water budget (see Dupont et al. 2006); and, last, the water surfaces "wat." Each surface type is characterized by its area density $f_{i}$, with $\Sigma_{i} f_{i}=1$, for $i \in$ (bare, nat, pav, roof, vega, vegn, wat) in each grid cell, and $f_{\text {vega }}=f_{\text {cova }}$.

SM2-U computes the water budget in three soil layers. The thin "surface layer" acts as a buffer for the evaporation from the surface and the precipitation water transfer to/from the (second) soil layer. This latter root-influenced layer contains the available water for vegetation transpiration. The subroot layer, or "deep soil layer," is used as a water reservoir to provide water to the root zone layer by diffusion in dry periods, as introduced by Boone et al. (1999) in the ISBA-3L version. There are two separate surface layers, under the bare surface (bare) and under the vegetated surface (nat + vegn), but one root zone cell and one deep soil layer cell per grid mesh (Fig. 1). For vegetation, roofs, and paved surfaces an interception reservoir defines the maximum amount of retained liquid water. When the reservoir overflows, the water runs off to the neighbor surfaces or to the draining network that is computed explicitly (Dupont 2001; Dupont et al. 2006). While roof surfaces are assumed fully impervious, paved surfaces are semi-impervious and let water infiltrate downward but not upward.

The surface energy budget is computed for each surface type in a cell:

$$
G_{s i}=R_{n i}-H_{\text {sens } i}-\mathrm{LE}_{i},
$$

where $R_{n}$ is the net radiation flux, $H_{\text {sens }}$ is the sensible heat flux, LE is the latent heat flux, and $G_{s}$ is the surface conduction heat flux toward soil/building materials computed as the residual of Eq. (1), which can be also assimilated to the heat storage by soil/building materials. To compute the aerodynamic heat fluxes $H_{\text {sensi }}$ and $\mathrm{LE}_{i}$, SM2-U determines the temperature $T_{s i}$ and specific humidity $q_{\mathrm{vs} i}$ of each surface type, and one deep soil temperature $T_{\text {soil }}$. Then the cell energy fluxes at the canopy-atmosphere interface are obtained by averaging the individual surface fluxes weighted by their area 


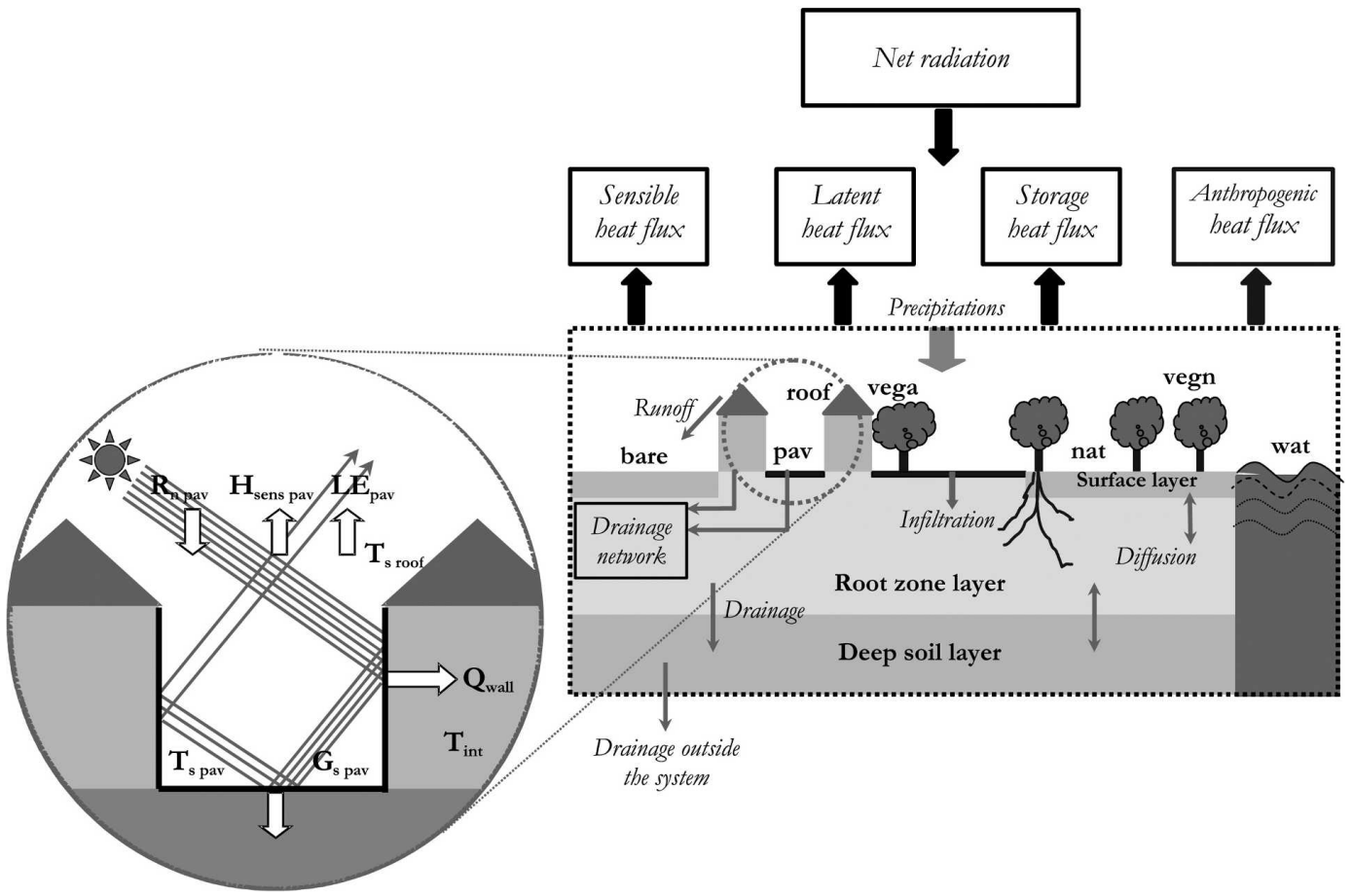

FIG. 1. Scheme of the SM2-U energy and water budget models with seven surface types (pav, bare, nat, roof, vega, vegn, wat) and three soil layers. The energy budget of paved surfaces is shown in the inset.

density, and by including anthropogenic heat fluxes released in the air of the canopy.

Surface temperature and heat flux equations of each surface type are described in sections $2 \mathrm{~b}$ and $2 \mathrm{c}$. The aerodynamic heat and humidity resistance computation is given in section $2 \mathrm{~d}$. Building walls and paved surfaces are coupled to calculate the street canyon energy budget as described in section 2e. The deep soil temperature calculation is given in section $2 \mathrm{f}$. The expressions of the mean heat fluxes and "aerodynamic" surface temperature $\theta_{s}$ at the canopy atmosphere interface are given in section $2 \mathrm{~g}$.

\section{b. Surface temperature equations}

The natural surface temperature $T_{s i}$ is calculated by means of a force-restore-type equation of the surface layer heat. The time evolution of $T_{s i}$ [Eq. (2)] appears as the sum of a forcing term resulting from the heat storage $G_{s i}$ and a relaxation term toward the equilibrium with the deep soil temperature $T_{\text {soil }}$ :

$$
\begin{aligned}
\frac{\partial T_{s i}}{\partial t} & =C_{T_{s i}} G_{s i}-\frac{2 \pi}{\tau}\left(T_{s i}-T_{\text {soil }}\right) \text { for } \\
i & \in \text { (bare, nat, vega, vegn), }
\end{aligned}
$$

where $C_{T_{s i}}$ is the inverse of the surface layer heat capacity and the parameter $\tau=86400 \mathrm{~s}$ is the day dura- tion. As in ISBA, Eq. (2) assumes that the surface layer is thin enough for the layer mean temperature and surface temperature to be equal.

For a rural area, while ISBA determines only one composite surface temperature, SM2-U distinguishes the vegetation $\left(T_{s \text { vegn }}\right)$ and soil surface temperatures $\left(T_{\text {snat }}\right)$. This modification has been introduced in view of the evaluation of heat fluxes from vegetation over paved surfaces. Indeed, computing a single temperature for a paved surface and vegetation, as it is done for soil surface and vegetation in ISBA, would be erroneous, because they behave so differently. The representation of sparse vegetation mixed with artificial surfaces is then as realistic as possible, especially in alternative scenarios of microclimatology. This modification in the original part of the model generates computational changes in calculation of mean surface temperature, and sensible and latent heat fluxes. The flux parameterizations are the same as in ISBA, although fluxes from the soil and from the vegetation are computed separately, and the evapotranspiration from each surface is computed at its own surface temperature, not the mean temperature. This transformation of SM2-U has been validated by Dupont et al. (2006) for rural areas by comparison with the experimental data from the Hydrologic Atmospheric Pilot Experiment-Modélisation du Bilan Hydrique (HAPEX-MOBILHY) and the Eu- 
ropean Field Experiment in a DesertificationThreatened Area (EFEDA) campaigns, showing that it does not degrade the model performances and allows for finer process discrimination in sensitivity analysis. Surface temperatures of vegetation over natural soil and over paved surfaces are processed in the same way, with the possibility to have different vegetation species (i.e., different parameter values) in a grid cell, whereas their water budget computation differs because surface water may runoff over bare soil and paved surface, respectively.

The force-restore model does not apply to artificial surfaces because thin surface materials respond rapidly to the environmental forcing while underlying materials have insulating thermal properties, unlike natural soils. For example, a restore term in roof temperature equation largely increases the heat transfer through the roof, which is generally weak for European buildings, circa $0.2 \mathrm{~W} \mathrm{~m}^{-2} \mathrm{~K}^{-1}$ (see section 2c). It is essentially the thin roof materials in contact with the atmosphere (and located above the insulating layer) which store/release heat during the diurnal cycle. Therefore, a normal heat conduction equation is used for artificial surface layers. Each artificial cover is represented by two layers. The superficial layer, referenced by the index $s$, allows the model to respond quickly to the environmental forcing variations, and the second, inner layer, referenced by the index "2," allows the artificial materials to store heat (see section $4 \mathrm{~b}$ ). In each layer, the heat budget is expressed as a temperature time evolution equation:

$$
\begin{aligned}
\frac{\partial T_{s i}}{\partial t}= & C_{T_{s i}}\left(G_{s i}-\delta_{i \text { roof }} Q_{\text {roof }}^{s \rightarrow 2}-\delta_{i \mathrm{pav}} Q_{\mathrm{pav}}^{\prime s \rightarrow 2}\right) \text { for } \\
i \in & (\text { pav, roof }) \text { and } \\
\frac{\partial T_{2 i}}{\partial t}= & C_{T_{2 i}}\left[\delta_{\text {iroof }}\left(Q_{\text {roof }}^{s \rightarrow 2}-Q_{\text {roof }}^{2 \rightarrow \text { int }}\right)\right. \\
& \left.+\delta_{i \text { pav }}\left(Q_{\text {pav }}^{\prime s \rightarrow 2}-Q_{\text {pav }}^{\prime 2 \rightarrow \text { int }}\right)\right] \text { for } \\
i \in & (\text { pav, roof }),
\end{aligned}
$$

where $\delta$ is the Kronecker's symbol ( $\delta_{i j}$ equals 1 for $i=$ $j$ and 0 otherwise), $G_{s i}$ is deduced from Eq. (1), $Q_{i}^{s \rightarrow 2}$ is the conduction flux between the surface and the second layer [Eq. (16)], and $Q_{i}^{2 \rightarrow \text { int }}$ is the conduction flux between the second layer and the building inside air [Eq. (17)] or the deep soil for paved surfaces [Eq. (18)]. The computation of the conduction fluxes between pavement layers is different from those between roof layers, as indicated by the prime superscript, because the first ones integrate the walls (see section 2e).

For bare soils and vegetation, the surface inverse heat capacity coefficients are the same as in ISBA:
$C_{T_{s i}}=C_{G_{\mathrm{sat}}}\left(w_{\mathrm{sat}} / w_{2}\right)^{b / \mathrm{n} 100}$ for $i \in($ bare, nat $)$ and

$C_{T_{s i}}=2 \times 10^{-5} \mathrm{~K} \mathrm{~m}^{2} \mathrm{~J}^{-1} \quad$ for $\quad i \in$ (vega, vegn),

where $w_{\text {sat }}$ is the saturated volumetric water content, $w_{2}$ is the volumetric water content of the root zone layer, and $b$ and $C_{G_{\text {sat }}}$ are empirical parameters.

For roofs, the inverse of the surface layer heat capacity $C_{T_{\text {jroof }}}$ depends on the thickness $e_{\text {jroof }}$ and on the volumetric heat capacity $C_{\text {jroof }}$ of the material layers:

$$
C_{T_{\text {jroof }}}=1 /\left(e_{j \text { roof }} C_{j \text { roof }}\right),
$$

where $j$ denotes either $s$ or 2 .

The inverse heat capacity of paved surfaces $C_{T_{\text {paav }}}$, which integrates the walls, is given in section 2e.

\section{c. Heat fluxes}

The energy fluxes are determined from the classical formulas presented below. First,

$$
R_{n i}=\left(1-\alpha_{i}\right) R_{G}+\varepsilon_{i} R_{A}-\varepsilon_{i} \sigma T_{s i}^{4},
$$

where $R_{G}$ is the global solar radiation (or incoming shortwave radiation), $R_{A}$ is the atmospheric radiation (or incoming longwave radiation), $\sigma$ is the StefanBoltzmann constant, and $\alpha_{i}$ and $\varepsilon_{i}$ are the surface albedo and emissivity. For simplification the albedo of sloping roofs is assumed equivalent to that of flat roofs. Next,

$$
H_{\mathrm{sens} i}=\rho_{\mathrm{air}} c_{p} \frac{1}{R_{\mathrm{ah} i}}\left(\theta_{s i}-\theta_{\mathrm{air}}\right),
$$

where $c_{p}$ is the specific heat of air at constant pressure, $R_{\mathrm{ah} i}$ is the aerodynamic heat resistance, $\theta_{s i}$ is the potential surface temperature, and $\rho_{\text {air }}$ and $\theta_{\text {air }}$ are the air density and potential temperature at the lowest atmospheric level (also called reference level).

The equations for the water vapor fluxes from vegetation and natural soils are identical to those of ISBA except that they use the surface-type temperature instead of the average temperature. The water vapor flux from the vegetation on natural soil $E_{\text {vegn }}$ (respectively, $E_{\text {vega }}$ on paved surface) is the sum of the evaporation of the intercepted water by the vegetation $E_{r \text { vegn }}$ (respectively, $\left.E_{r v e g a}\right)$ and of the vegetation transpiration $E_{\text {trvegn }}$ (respectively, $E_{\text {trvega }}$ ):

$$
\begin{aligned}
E_{i} & =E_{r i}+E_{\mathrm{tr} i}, \\
E_{r i} & =\frac{\rho_{\mathrm{air}} \delta_{i}}{R_{\mathrm{aq} i}}\left[q_{\mathrm{vsat}}\left(T_{s i}\right)-q_{\mathrm{vair}}\right], \quad \text { and }
\end{aligned}
$$




$$
E_{\mathrm{tr} i}=\frac{\rho_{\mathrm{air}}\left(1-\delta_{i}\right)}{R_{\mathrm{aq} i}+R_{s i}}\left[q_{\mathrm{usat}}\left(T_{s i}\right)-q_{\mathrm{vair}}\right],
$$

where $i \in$ (vega, vegn), $\delta_{i}$ is the vegetation surface wet portion, $R_{\text {aqi }}$ and $R_{s i}$ are the aerodynamic humidity and stomatal resistances, $q_{\text {vsat }}$ is the surface-saturated specific humidity of the air, and $q_{\text {vair }}$ is the air specific humidity at the reference level.

For natural soils, the water vapor flux depends on the relative humidity $h_{u i}$ at the ground surface:

$$
E_{i}=\frac{\rho_{\mathrm{air}}}{R_{\mathrm{aq} i}}\left[h_{u i} q_{\text {vsat }}\left(T_{s i}\right)-q_{\text {vair }}\right] \text { for } i \in \text { (bare, nat). }
$$

The water vapor fluxes from artificial surfaces are determined in the same way as the evaporation fluxes from the vegetation, by extending the concept of the vegetation surface wet portion to urban surfaces:

$$
\begin{aligned}
E_{i} & =\frac{\rho_{\text {air }} \delta_{i}}{R_{\mathrm{aq} i}}\left[q_{\mathrm{usat}}\left(T_{s i}\right)-q_{\text {vair }}\right] \text { for } \\
i & \in \text { (pav, roof). }
\end{aligned}
$$

At water surfaces, the air being saturated, the water vapor flux writes as

$$
E_{\text {wat }}=\frac{\rho_{\text {air }}}{R_{\text {aqwat }}}\left[q_{\text {vsat }}\left(T_{\text {swat }}\right)-q_{\text {vair }}\right] .
$$

For Eqs. (11)-(15), a dew flux may occur when $q_{\text {vsat }}\left(T_{s i}\right)$ $<q_{\text {vair }}: \delta_{i}$ and $h_{\mathrm{u} i}$ are then set to 1 .

The surface internal heat flux $Q_{i}^{s \rightarrow 2}$ corresponds to the heat transfer between the superficial layer and the second layer of artificial materials. This flux depends on the thickness $e_{j i}$, heat conductivity $\lambda_{j i}$, and temperature of the two layers:

$$
\begin{aligned}
Q_{i}^{s \rightarrow 2} & =\frac{e_{s i}+e_{2 i}}{e_{s i} \lambda_{s i}^{-1}+e_{2 i} \lambda_{2 i}^{-1}} \frac{T_{s i}-T_{2 i}}{0.5\left(e_{s i}+e_{2 i}\right)} \text { for } \\
i & \in \text { (pav, roof) } .
\end{aligned}
$$

The second internal heat flux $Q_{i}^{2 \rightarrow \text { int }}$ corresponds to the heat transfer between the second layer of artificial materials and either the air inside buildings, or the soil under paved surfaces. It depends on the material averaged heat transfer coefficient $K_{i}$ and the temperature difference:

$$
\begin{aligned}
& Q_{\text {roof }}^{2 \rightarrow \text { int }}=-K_{\text {roof }}\left(T_{2 \text { roof }}-T_{\text {int }}\right) \quad \text { and } \\
& Q_{\text {pav }}^{2 \rightarrow \text { int }}=-K_{\text {pav }}\left(T_{2 \text { pav }}-T_{\text {soil }}\right),
\end{aligned}
$$

where $T_{\mathrm{int}}$ is the air temperature inside buildings, which was fixed to $301 \mathrm{~K}$ for the Marseille city center.

As suggested by Recknagel and Sprenger (1995), in first approximation $K_{\text {roof }}$ depends only on the insulating layer:

$$
K_{\text {roof }} \approx \lambda_{\text {iso }} / e_{\text {iso }},
$$

where $e_{\text {iso }}$ is the insulating layer thickness and $\lambda_{\text {iso }}$ is its thermal conductivity. For an insulating layer of polyurethane foam with $\lambda_{\text {iso }}=0.029 \mathrm{~W} \mathrm{~m}^{-1} \mathrm{~K}^{-1}$ and $e_{\text {iso }}=$ $0.150 \mathrm{~m}, K_{\text {roof }}$ is equal to $0.2 \mathrm{~W} \mathrm{~m}^{-2} \mathrm{~K}^{-1}$.

\section{d. Aerodynamic heat and humidity resistances}

Aerodynamic heat and humidity resistances $R_{\mathrm{ah} i}$ and $R_{\text {aq } i}$, which appear in the sensible heat and water vapor flux equations, depend on the wind velocity at the reference level and on the heat and water vapor transfer coefficients, respectively. Heat transfer coefficients are calculated following the noniterative algorithm of Guilloteau (1998) for nonequal momentum and heat roughness lengths $z_{0 m i}$ and $z_{0 h i}$, respectively. Guilloteau's method is based on a combination of the Högström (1996) and Beljaars and Holtslag (1991) formulations of the flux-profile relationships. It is inspired by the Launiainen (1995) method for stable stratification and generalizes the Byun (1990) method for unstable stratification. The exchange coefficient is thus deduced from the integrated Monin-Obukhov similarity theory between a reference level and a surface aerodynamic level. Here the humidity transfer coefficient is set equal to that of heat. The surface temperatures computed with the above energy budget equations are assumed to be the skin temperatures, but not the aerodynamic temperatures at canopy-top level. To solve the problem of inconsistency between skin and aerodynamic temperatures, the heat roughness length is not assumed equal to the momentum roughness length. This difference between $z_{0 m i}$ and $z_{0 h i}$ is generally characterized by the parameter $k_{B i}^{-1}=\ln \left(z_{0 m i} / z_{0 h i}\right)$. For rural areas $k_{B i}^{-1}$ is around 2, whereas for an urban area Voogt and Grimmond (2000) found values between 20 and 27. There is no agreement on the value of $k_{B i}^{-1}$, especially in urban areas where the surface heterogeneity accentuates the difficulty to evaluate $z_{0 h i}$. Few parameterizations of $k_{B i}^{-1}$ exist in the literature (see Voogt and Grimmond 2000 and Piringer and Joffre 2005 for a review). As in the National Centers for Environmental Prediction Mesoscale Eta Model (Chen et al. 1997), the Reynolds number-dependent formulation of Zilitinkevich (1995) is implemented in SM2-U, with this relationship having the advantage of being simple and related to the flow properties:

$$
z_{0 m i} / z_{0 h i}=\exp \left(\kappa C \sqrt{\mathrm{Re}_{i}^{*}}\right),
$$

where $\kappa$ is the von Kármán constant $(\kappa=0.4)$ and $\mathrm{Re}_{i}^{*}=z_{0 m i} u_{* i} / \nu$ is the roughness Reynolds number, 
with $u_{* i}$ being the friction velocity and $\nu$ the kinematic molecular viscosity of the air $\left(1.461 \times 10^{-5} \mathrm{~m}^{2} \mathrm{~s}^{-1}\right)$; $C$ is an empirical constant, set to 0.1 as recommended by Chen et al. (1997).

\section{e. The urban canopy influence}

The canopy-atmosphere interface is a folded surface, a complex three-dimensional arrangement of many vertical artificial surfaces (buildings) among horizontal artificial and natural surfaces (pavement, bare soil, vegetation, water). This structure has a significant effect on the energy budget, especially by increasing the heat storage capacity. During the day, in some districts, the heat storage in the artificial materials may be higher than the sensible heat flux, as observed by Oke et al. (1999) in the central Mexico City, Mexico. During the night, this heat is released to the atmosphere, counterbalancing the negative net radiation and keeping the canopy layer warmer than the rural surroundings. In turn, this reduces the negative sensible heat flux and the lower-layer atmospheric stratification, generating most of the urban heat island. The nocturnal sensible heat flux may even remain positive in city centers.

The three-dimensional structure heterogeneity and complexity of the canopy make it impossible to compute explicitly all of the physical processes, such as subgrid-scale atmospheric advection or canopy wind flow, in mesoscale atmospheric models. The model canopy in SM2-U can be seen as a flat canopy where the vertical dimension is considered through the integration of building walls with paved surfaces in a street canyon energy budget (Fig. 1, inset). Thus, the surface temperature of paved surfaces $T_{s \text { pav }}$ corresponds to an effective mean temperature of the street canyon surfaces. From Eqs. (3)-(4) $T_{\text {spav }}$ and $T_{2 \mathrm{pav}}$ are deduced. Building walls are accounted for in the following three ways: first, the energy budget includes the heat flux through the walls; second, the pavement heat capacity includes the storage capacity of walls; third, the radiative trapping inside the street is modeled in the effective albedo and emissivities, which depend on those of the street materials and on the canyon geometry.

The turbulent exchange of heat from the canyon surfaces and the air above the canyon is still at research stage despites the recent works of Barlow and Belcher (2002), Harman et al. (2004), and Hagishima et al. (2005). In some models (Masson 2000; Kusaka et al. 2001) the canyon heat transfer coefficient is computed as two resistances in series-the first one between canyon surfaces and the canyon air, and the second one between the canyon air and the atmosphere above. However, these resistances are deduced from empirical formulations (Rowley et al. 1930) that are still uncertain. The former resistance depends on rough parameterizations of the vertical wind speed along the walls and of the horizontal canyon wind speed. It is well known that wind velocity is strongly variable within the canopy with the formation of recirculation and ventilated regions (Harman et al. 2004); it depends on the overlying wind direction (relative to the canyon axis) (Rotach 1995) and on the aspect ratio of the canyon (Rotach 1995; Barlow and Belcher 2002; Hagishima et al. 2005). In addition, street canyon remains a theoretical basic geometric unit that may not be realistic because it neglects street junctions and assumes a street of infinite length and buildings of uniform height with flat roofs. For all of these reasons, we decide to keep a simple approach by computing the heat transfer coefficients from the heat roughness length formulation, which depends on the atmospheric stability, as presented in the previous subsection, and by assuming that the heat transfer coefficients of the horizontal and vertical surfaces of the street are equal, with more detailed parameterizations being still very uncertain (Louka et al. 2002). However, Masson et al. (2002) observed that replacing Rowley et al.'s (1930) formulation by the roughness length formulation for road improved the surface temperature evaluation. The assumption of equal heat transfer coefficients of the horizontal and vertical surfaces is a simplification whose consequences are not obvious and may require revision in the future.

The conduction heat fluxes between pavement layers in Eqs. (3)-(4) integrate the walls by introducing the heat fluxes through building walls $Q_{\text {wall }}^{s \rightarrow 2}$ and $Q_{\text {wall }}^{2 \rightarrow \text { int }}$, weighted by the wall-to-paved area ratio:

$$
\begin{gathered}
Q_{\mathrm{pav}}^{\prime s \rightarrow 2}=Q_{\mathrm{pav}}^{s \rightarrow 2}+\frac{S_{\mathrm{wall}}}{S_{\mathrm{pav}}} Q_{\text {wall }}^{s \rightarrow 2} \text { and } \\
Q_{\mathrm{pav}}^{\prime \rightarrow \rightarrow \text { int }}=Q_{\mathrm{pav}}^{2 \rightarrow \text { int }}+\frac{S_{\text {wall }}}{S_{\text {pav }}} Q_{\text {wall }}^{2 \rightarrow \text { int }},
\end{gathered}
$$

where $Q_{\mathrm{pav}}^{s \rightarrow 2}, Q_{\mathrm{wall}}^{s \rightarrow 2}, Q_{\mathrm{pav}}^{2 \rightarrow \text { int }}$, and $Q_{\mathrm{wall}}^{2 \rightarrow \text { int }}$ are deduced from Eqs. (16), (24), (18), and (25), respectively; $S_{\text {wall }}$ and $S_{\text {pav }}$ are the total area of building walls and of paved surfaces (minus vegetation-covered area) in the cell. In practice, their ratio is computed from the street canyon aspect ratio:

$$
S_{\mathrm{wall}} / S_{\mathrm{pav}}=2 H / W
$$

where $H$ and $W$ are, respectively, the average height and width of the streets in the cell.

The heat fluxes through building walls $Q_{\text {wall }}^{s \rightarrow 2}$ and $Q_{\text {wall }}^{2 \rightarrow \text { int }}$ are calculated in the same way as those through building roofs: 


$$
Q_{\text {wall }}^{s \rightarrow 2}=\frac{e_{s w a l l}+e_{2 \text { wall }}}{e_{s w a l l} \lambda_{s w a l l}{ }^{-1}+e_{2 \text { wall }} \lambda_{2 \text { wall }}{ }^{-1}} \frac{T_{s \text { pav }}-T_{2 \text { pav }}}{0.5\left(e_{s w a l l}+e_{2 \text { wall }}\right)} \quad \text { and }
$$

$$
Q_{\text {wall }}^{2 \rightarrow \text { int }}=K_{\text {wall }}\left(T_{2 \text { pav }}-T_{\text {int }}\right),
$$

where $\lambda_{\text {wall }}$ is the heat conductivity of the considered wall layer and $K_{\text {wall }}$ is the heat transfer coefficient between the second wall layer and the air inside the building. As for roofs, $K_{\text {wall }}$ depends essentially on the insulating layer.

The street canyon surface and second layer inverse heat capacities $C_{T_{\text {ipav }}}$, appearing in Eqs. (3)-(4), are represented by two resistances in parallel for the walls resistance $C_{T_{\text {jwall }}}$ and paved surfaces $C_{T_{\text {jfloor }}}$ ( $j$ denotes either $s$ or 2):

$$
C_{T_{j \mathrm{pav}}}=1 /\left(\frac{S_{\mathrm{wall}}}{S_{\mathrm{pav}}} \frac{1}{C_{T_{j \mathrm{wall}}}}+\frac{1}{C_{T_{j \mathrm{floor}}}}\right),
$$

with

$$
C_{T_{j \mathrm{wall}}}=1 /\left(e_{j \mathrm{wall}} C_{j \mathrm{wall}}\right) \quad \text { and } \quad C_{T_{j \mathrm{pav}}}=1 /\left(e_{j \mathrm{pav}} C_{j \mathrm{pav}}\right),
$$

where $e_{j \text { wall }}$ and $e_{j \mathrm{pav}}$ are the thickness of the wall and pavement layers, respectively, and $C_{j \text { wall }}$ and $C_{j p a v}$ are their volumetric thermal capacities.

The radiative trapping is modeled by introducing into the net radiation flux $R_{n \text { pav }}$, an effective albedo $\alpha_{\text {pav }}^{\text {eff }}$, and two effective emissivities for the atmospheric radiation $\varepsilon_{\text {pav }}^{\text {Aeff }}$ and for the infrared radiation $\varepsilon_{\text {pav }}^{\text {IReff }}$. The effective albedo and emissivities depend on wall and paved surface albedos and emissivities, respectively, and on the height-to-width aspect ratio of the street canyon $(H / W)$. In addition, the effective albedo depends on the sun zenith angle and azimuth angle with respect to the average street axis direction. The parameterizations of these effective albedo and emissivities are adapted from Masson's (2000) calculations as shown in the appendix. Thus,

$$
R_{n \text { pav }}=\left(1-\alpha_{\text {pav }}^{\text {eff }}\right) R_{G}+\varepsilon_{\text {pav }}^{\text {Aeff }} R_{A}-\varepsilon_{\mathrm{pav}}^{\text {IReff }} \sigma T_{s p a v}^{4} .
$$

The street canyon evaporation flux corresponds to the evaporation of the water collected by paved surfaces, that is, the wall water collection is neglected.

The terms representing the wall influence into $C_{T_{\text {ipav }}}$, $Q_{\mathrm{pav}}^{\prime s \rightarrow 2}$, and $Q_{\mathrm{pav}}^{\prime 2 \rightarrow \text { int }}$ are weighted by the wall-to-pavedarea ratio. Thus, for a district with paved surfaces without buildings, the equation of $T_{j \mathrm{pav}}$ is similar to that of a bare paved surface, because the albedo and emissivity corrections vanish when $H / W=0$. For a district where artificial and natural surface areas are equivalent, for example, a residential district, although buildings are not located along paved surfaces and do not constitute street canyons, strictly speaking, the same calculation is still applied. However, Dupont (2001) showed that for residential districts where the wall-area ratio is generally small the wall influence on the energy budget and on the surface temperature of the district is small.

\section{f. Deep soil temperature}

The deep soil temperature is determined by a returnto-equilibrium equation toward an average temperature of all surfaces in contact with the soil. The soil located just below buildings is assumed at the same temperature as the deep soil. Thus,

$$
\frac{\partial T_{\text {soil }}}{\partial t}=\frac{1}{\tau}\left(\frac{f_{\text {nat }} T_{\text {snat }}+f_{\text {pav }} T_{2 \mathrm{pav}}+f_{\text {roof }} T_{\text {soil }}+f_{\text {bare }} T_{\text {sbare }}+f_{\text {vegn }} T_{\text {svegn }}+f_{\text {vega }} T_{\text {svega }}}{1-f_{\text {wat }}}-T_{\text {soil }}\right) .
$$

\section{g. Canopy budget}

The main outputs of the model are the fluxes at the canopy-atmosphere interface of a computational cell for either a (sub)mesoscale model or of a representative domain for a comparison with experimental data obtained at an urban site.

The net radiation flux of the cell is the weighted average of the effective net radiation fluxes of all underlying surfaces:

$$
R_{n}=\sum_{i} f_{i} R_{n i}
$$

where $i \in$ (pav, bare, nat, roof, vega, vegn, wat).

The shortwave and longwave radiation emitted by the canopy, $S \uparrow$ and $L \uparrow$, respectively, are computed as follows:

$$
\begin{gathered}
S \uparrow=\sum_{i} f_{i} \alpha_{i} R_{G}+f_{\mathrm{pav}} \alpha_{\mathrm{pav}}^{\mathrm{eff}} R_{G} \quad \text { and } \\
L \uparrow=\sum_{i}\left[\left(1-\varepsilon_{i}\right) R_{A}+\varepsilon_{i} \sigma T_{s i}^{4}\right] f_{i}+\left[\left(1-\varepsilon_{\mathrm{pav}}^{\mathrm{Aeff}}\right) R_{A}\right. \\
\left.+\varepsilon_{\mathrm{pav}}^{\mathrm{IRpav}} \sigma T_{\text {spav }}^{4}\right] f_{\mathrm{pav}} .
\end{gathered}
$$


The surface conduction heat flux is computed with a similar formula as $R_{n}$ :

$$
G_{s}=\sum_{i} f_{i} G_{s i}
$$

The set of Eqs. (1)-(33) allows for computation of the energy exchanges between the lower atmosphere and the solid (and liquid) materials of the ground and buildings, hence the surface energy budget at the folded surface of the city.

In practice, when using SM2-U for computing the lower boundary forcing of an atmospheric model the canopy-atmosphere interface is assumed an horizontal surface somewhere in the air immediately above the roof level, or at the blending height above the roughness sublayer to comply with Monin-Obukhov similarity (see discussion in Piringer and Joffre 2005). Also, when the model performances are compared with measurements it is important to keep in mind that the radiation sensors measure the fluxes at the material surface while the turbulence sensors measure the aerodynamic fluxes at some elevation above the roof level, typically at $z=2-3 H$, with a possible divergence between the two levels (see discussion in Pigeon et al. 2003).

When computing the energy budget at the canopyatmosphere interface, Eqs. (30) and (33) may be used, assuming that the heat storage in the air of the canopy layer can be neglected when compared with the heat storage in the solid materials. It must also be noted that, while over natural grounds the integral of $G_{s}$ over a long period of time (typically a year) is close to zero, this is not the case over the cities because the buildings are energy-consuming systems and the time integral of $G_{s}$ is equal to this energy consumption.

The sensible and latent heat fluxes at the top of the canopy differ from the surface fluxes in the presence of additional anthropogenic sources in the canopy like, for example, a density of vehicles as in the case of Marseille city center comparison of the next section. Neglecting their interaction with the surfaces, their sensible and latent heat contributions may be added to the surface fluxes, yielding

$$
\begin{aligned}
H_{\mathrm{sens}} & =Q_{\mathrm{anth} H}^{\uparrow}+\sum_{i} f_{i} H_{\mathrm{sens} i} \text { and } \\
\mathrm{LE} & =Q_{\mathrm{anth} E}^{\uparrow}+\sum_{i} f_{i} \mathrm{LE}_{i} .
\end{aligned}
$$

Usually the fluxes $H_{\text {sens }}$ and LE are the boundary forcing terms in atmospheric simulation models. Alternately, in some models the forcing is given under the form of the "aerodynamic" surface temperature at the canopy-atmosphere interface of the computational cell.
This is another model output, determined by assuming a relation similar to the inverse of Eq. (9) consistently with the interface flux of Eq. (34):

$$
\theta_{s}=\theta_{\mathrm{air}}+\frac{R_{\mathrm{ah}}}{\rho_{\mathrm{air}} c_{p}}\left(Q_{\mathrm{anth} H}^{\uparrow}+\sum_{i} f_{i} H_{\mathrm{sens} i}\right),
$$

where $\theta_{\text {air }}$ is the air temperature at the lowest grid level of the atmospheric model and $R_{\mathrm{ah}}$ is the aerodynamic heat resistance of the whole canopy, obtained with Guilloteau's (1998) algorithm (see section 2d) and the previous time step value of $\theta_{s}$. It must be noted that $\theta_{s}$ is neither the air temperature at the interface level nor the radiative surface temperature.

\section{Model validation on the Marseille city center}

\section{a. Description of the field measurements}

In this section, the model is compared with the Marseille city center flux measurements collected during the UBL-ESCOMPTE campaign (Mestayer et al. 2005) by the groups from the Universities of Indiana, British Columbia, and Western Ontario, and MétéoFrance (CNRM) (Grimmond et al. 2004). The meteorological conditions of this campaign are characterized by an alternation of land/sea breeze and windy conditions, with nearly all sunny days (Cros et al. 2004). A previous validation of the TEB model has been performed by Lemonsu et al. (2004) with this dataset, and SM2-U is evaluated for the same period and with the same morphological parameters (see Lemonsu et al. 2004, for details).

Briefly, the site is characterized by a low vegetation cover $(13.6 \%)$ consisting of trees and short vegetation on natural soil, with tall roughness elements (59.5\%) corresponding to buildings from four to six stories in height, mostly surrounded by pavements $(26.9 \%)$. This district is typical of old European cities: there is a large density of buildings separated by narrow streets $(H / W=1.63)$. The building roofs are mostly covered with tiles and to a lesser extend with a gravel layer above concrete. Pavements are mostly asphalt and concrete.

A Hilomast NX30 pneumatic tower was installed on the roof of the Cour d'Appel Administrative located at $43^{\circ} 17^{\prime} \mathrm{N}, 5^{\circ} 22^{\prime} \mathrm{E}$. The tower was operated at two heights according to wind intensity. Air temperature and humidity, wind speed, pressure, and sensible and latent heat fluxes have been measured at 43.9 (upper level) and 37.9 (lower level) $\mathrm{m}$. The atmospheric, solar, and net radiations have been measured at $37.9 \mathrm{~m}$. The sensible and latent heat fluxes have been measured using the eddy covariance technique with R. M. Young Com- 
pany sonic anemothermometers and Li-Cor, Inc., $\mathrm{H}_{2} \mathrm{O} /$ $\mathrm{CO}_{2}$ sensors, sampled at $10 \mathrm{~Hz}$ and averaged over $1 \mathrm{~h}$. The storage heat flux has been calculated as the residual of the energy balance and it accumulates measurement errors and neglected terms. Measurements have been recorded during 24 days from 18 June to 11 July 2001.

\section{b. Simulation setup}

Because Marseille's downtown is homogeneous, the shifting source area that influences the turbulent fluxes measurements is considered as a circular domain around the tower (see Fig. 1 of Grimmond et al. 2004). This choice relies on the study of Lemonsu et al. (2004) who demonstrated that the dynamic source area concept of Schmid and Oke (1990) is unnecessary here because of the surface homogeneity. The SM2-U computational domain is thus composed of a single cell representing the circular domain around the tower-1000 $\mathrm{m}$ in diameter. The model is used in stand-alone mode, by constraining the atmospheric inputs (pressure, temperature, humidity, wind speed, precipitation, and radiation) [see Fig. 2 of Grimmond et al. (2004) for their variation along the period] at the middle of the cell, at a level moving during the calculation according to the tower position, to follow the observations. Because the third intense observation period (1-4 July) was not yet available at the time of Lemonsu et al.'s (2004) simulations, for the sake of comparison between our model and TEB, the results average the simulations of the 18-30 June and 5-11 July periods, corresponding actually to 21 days in total. Simulations were started at 0000 UTC 18 June without spinup time. The soil water contents were initialized at field capacity and the soil temperature at $17^{\circ} \mathrm{C}$ as proposed by Lemonsu (2003). Surface temperatures were initialized with the air temperature, which seems a reasonable assumption at midnight.

Table 1 summarizes the parameter values used in this model validation. The values of the heat transfer coefficients of roof, wall, and paved surfaces are those of the third and fourth layers of the corresponding artificial materials in Lemonsu's (2003) study with the TEB model. The anthropogenic heat flux of Lemonsu et al. (2004) is also imposed here. Mostly because of the car traffic this flux is characterized by peak values of $15 \mathrm{~W}$ $\mathrm{m}^{-2}$ in the morning (around 0700 UTC) and in the evening (around 1600 UTC), and a mean value of $12 \mathrm{~W}$ $\mathrm{m}^{-2}$ during the day and $2 \mathrm{~W} \mathrm{~m}^{-2}$ at night.

The conventional flux representation is used here in the figures, with positive values for downward radiation and storage fluxes and for upward aerodynamic and released heat fluxes. The time is coordinated universal time, delayed by $22 \mathrm{~min}$ from the local solar time.
TABLE 1. Values of the parameters used by SM2-U to represent Marseille downtown (MD).

\begin{tabular}{|c|c|c|}
\hline Parameter & Unit & MD \\
\hline$f_{\text {vega }}$ & - & 0.00 \\
\hline$f_{\text {vegn }}$ & - & 0.1292 \\
\hline$f_{\text {nat }}$ & - & 0.0068 \\
\hline$f_{\text {bare }}$ & - & 0.00 \\
\hline$f_{\text {roof }}$ & - & 0.595 \\
\hline$f_{\text {pav }}$ & - & 0.269 \\
\hline$f_{\text {wat }}$ & - & 0.00 \\
\hline$z_{0 m}$ & $\mathrm{~m}$ & 1.90 \\
\hline \multirow[t]{2}{*}{$H / W$} & - & 1.63 \\
\hline & Roof (tile-concrete) & \\
\hline$z_{\text {omroof }}$ & $\mathrm{m}$ & 0.15 \\
\hline$\alpha_{\text {roof }}$ & - & 0.22 \\
\hline$\varepsilon_{\text {roof }}$ & - & 0.90 \\
\hline$K_{\text {roof }}$ & $\mathrm{W} \mathrm{m}^{-2} \mathrm{~K}^{-1}$ & 0.52 \\
\hline$\lambda_{\text {roofs }}, \lambda_{\text {roof2 }}$ & $\mathrm{W} \mathrm{m}{ }^{-1} \mathrm{~K}^{-1}$ & $0.90,0.93$ \\
\hline$C_{\text {roofs }}, C_{\text {roof2 }}$ & $\mathrm{MJ} \mathrm{m}^{-3} \mathrm{~K}^{-1}$ & $1.77,1.50$ \\
\hline \multirow[t]{2}{*}{$e_{\text {roofs }}, e_{\text {roof2 }}$} & $\mathrm{m}$ & $0.02,0.15$ \\
\hline & Paved surface (asphalt) & \\
\hline$z_{0 m \text { pav }}$ & $\mathrm{m}$ & 0.05 \\
\hline$\alpha_{\text {pav }}$ & - & 0.08 \\
\hline$\varepsilon_{\mathrm{pav}}$ & - & 0.94 \\
\hline$K_{\text {pav }}$ & $\mathrm{W} \mathrm{m}^{-2} \mathrm{~K}^{-1}$ & 0.40 \\
\hline$\lambda_{\text {pavs }}^{\text {pav }}, \lambda_{\text {pav2 }}$ & $\mathrm{W} \mathrm{m} \mathrm{m}^{-1} \mathrm{~K}^{-1}$ & $0.66,2.10$ \\
\hline$C_{\text {pavs }}, C_{\text {pav2 }}$ & $\mathrm{MJ} \mathrm{m}^{-3} \mathrm{~K}^{-1}$ & $1.83,2.00$ \\
\hline \multirow[t]{2}{*}{$e_{\mathrm{pavs}}, e_{\mathrm{pav} 2}$} & $\mathrm{~m}$ & $0.04,0.20$ \\
\hline & Wall (stone-concrete) & \\
\hline$\alpha_{\text {wall }}$ & - & 0.20 \\
\hline$\varepsilon_{\text {wall }}$ & - & 0.90 \\
\hline$K_{\text {wall }}$ & $\mathrm{W} \mathrm{m}^{-2} \mathrm{~K}^{-1}$ & 2.84 \\
\hline$\lambda_{\text {walls }}, \lambda_{\text {wall2 }}$ & $\mathrm{W} \mathrm{m}{ }^{-1} \mathrm{~K}^{-1}$ & $1.77,1.77$ \\
\hline$C_{\text {walls }}, C_{\text {wall2 }}$ & $\mathrm{MJ} \mathrm{m}^{-3} \mathrm{~K}^{-1}$ & $1.89,1.89$ \\
\hline \multirow[t]{2}{*}{$e_{\text {walls }}, e_{\text {wall2 }}$} & $\mathrm{m}$ & $0.01,0.04$ \\
\hline & Natural surface (trees, shrubs) & \\
\hline Soil type & - & Clay loam ${ }^{\mathrm{a}}$ \\
\hline Leaf area index & - & 3.00 \\
\hline$z_{0 m \text { nat }} ; z_{0 m \mathrm{vegn}}$ & $\mathrm{m}$ & 0.65 \\
\hline$\alpha_{\text {vegn }}$ & - & 0.15 \\
\hline$\varepsilon_{\text {vegn }}$ & - & 0.97 \\
\hline$w_{\text {sat }}$ & $\mathrm{m}^{3} \mathrm{~m}^{-3}$ & 0.469 \\
\hline$w_{\mathrm{fc}}^{\mathrm{b}}$ & $\mathrm{m}^{3} \mathrm{~m}^{-3}$ & 0.302 \\
\hline$w_{\text {wilt }} \mathrm{c}$ & $\mathrm{m}^{3} \mathrm{~m}^{-3}$ & 0.213 \\
\hline
\end{tabular}

a See the soil parameter values for the "clay loam" category in Noilhan and Planton (1989) and Boone et al. (1999).

${ }^{\mathrm{b}}$ Field capacity volumetric water content.

${ }^{\mathrm{c}}$ Volumetric water content at wilting point.

To quantify model performances Willmott (1982) recommended the root-mean-square error (rmse) and its systematic error fraction (rmses), where rmse $=$ $\left[\sum_{i=1}^{n}\left(s_{i}-o_{i}\right)^{2} / n\right]^{1 / 2}$, where $s_{i}$ and $o_{i}$ are the simulated and observed values, respectively, and $n$ is the number of observations, and rmses $=\left[\sum_{i=1}^{n}\left(\hat{s}_{i}-o_{i}\right)^{2} / n\right]^{1 / 2}$, where $\hat{s}_{i}$ is the value of the linear least squares regression fit to the $s_{i}$ vs $o_{i}$ dataset. The systematic error part is expected 


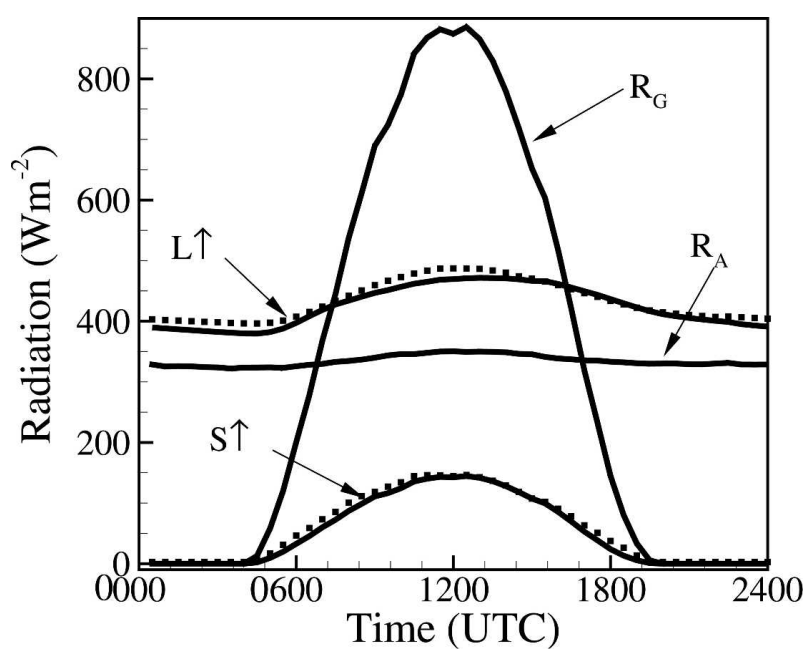

FIG. 2. Comparison on an average diurnal cycle between the simulated (solid line) and observed (dots) shortwave $(S \uparrow)$ and longwave $(L \uparrow)$ outgoing radiations. The incoming shortwave $\left(R_{G}\right)$ and longwave $\left(R_{A}\right)$ radiations are also indicated.

to quantify the processes that the model routinely simulates in a wrong way, whereas unsystematic errors could be attributed to randomness or subgrid-scale processes (Otte et al. 2004). A "good" model should have a systematic error approaching zero.

\section{c. Comparison between simulations and observations}

\section{1) Average fluXes over a 21-DAy PERIOD}

The simulated average diurnal cycles of the radiation and energy budget components are separately compared with the observations in Figs. 2 and 3. The rmse values of the model budget components are presented in Fig. 4, where the shaded areas indicate the systematic error fractions.

Figure 2 compares the observed and simulated average diurnal cycles of the shortwave and longwave radiation $S \uparrow$ and $L \uparrow$, respectively. The incoming shortwave and longwave radiation are also indicated; they have been measured at the city center site and are used as SM2-U model inputs. For both outgoing radiation the SM2-U simulations are very close to observations. Rmse values for the overall period are 10 and $14 \mathrm{~W}$ $\mathrm{m}^{-2}$, respectively (Fig. 4a). A small fraction of these rmse corresponds to systematic errors-37\% and 10\%, respectively. The night/day rmse comparison of Fig. 4 shows that the SM2-U simulation accuracy is the same throughout the day. However, the systematic error fraction of the outgoing longwave radiation is higher at night $(26 \%)$ than during daytime $(10 \%)$. Indeed, in Fig. $2 L \uparrow$ seems slightly underestimated at night, probably because of a too-low simulated surface temperature. Also $S \uparrow$ seems slightly underestimated in the few hours after sunrise and before sunset, and this may be due to an underestimation of the albedo. Nevertheless the comparison between the simulated and observed net radiation (Fig. 3a) confirms that SM2-U simulates accurately the net radiation budget. The net radiation rmse is $21 \mathrm{~W} \mathrm{~m}^{-2}$ for the overall period with a systematic error fraction of $37 \%$ (Fig. 4a). The rmse is slightly less at night than in the daytime, but when compared with the net radiation amplitudes the systematic error appears relatively larger at night. This may be explained by the larger influence of the simulated surface temperature on the net radiation calculation at night than during daytime.

The mean diurnal cycle latent heat flux seems well simulated (Fig. 3b), but the Rmse appears very large when compared with flux values-42 $\mathrm{W} \mathrm{m}^{-2}$ for the overall period (Fig. 4a) - and the systematic error fraction is also very large-83\%. Despite the SM2-U's ability to reproduce the average daily cycle of the latent heat flux, instantaneous values are not accurately simulated, as shown in the next section.

The mean diurnal cycle of the sensible heat flux is very well simulated (Fig. 3c), with reasonable values of the rmse of $66 \mathrm{~W} \mathrm{~m}^{-2}$ for the overall period (Fig. 4a). The rmse is smaller during nighttime than during daytime, respectively, 87 and $31 \mathrm{~W} \mathrm{~m}^{-2}$. The small systematic error fraction $(7 \%)$ for the overall period confirms that SM2-U simulates adequately the sensible heat transfer processes. However, the nocturnal systematic error fraction is relatively larger $(66 \%)$ because the nocturnal sensible heat flux is always underestimated by a few watts per squared meter. This may be due to an underestimation of the nocturnal surface temperature, as noted with the outgoing longwave radiation, or to an underestimation of the anthropogenic heat flux.

However, the model is able to represent the nocturnal positive values of the sensible heat flux induced by the heat release by artificial surfaces, which is characteristic of the urban energy budget. Note that the sensible heat flux is slightly underestimated just after sunrise.

Both the simulated and observed storage heat fluxes are the residuals in the energy balance, and therefore they both accumulate the errors of the other heat fluxes (actually, in the model the imbalance aspect of the $G_{s i}$ is more apparent than real one because these fluxes are also coupled with the other fluxes through the $T_{s i}$ equations). In SM2-U simulations the average storage heat flux behaves well like the flux deduced from the observations. The overall rmse is equal to $70 \mathrm{~W} \mathrm{~m}^{-2}$ with a systematic error fraction of $35 \%$ (Fig. 4a). It appears in 
a)

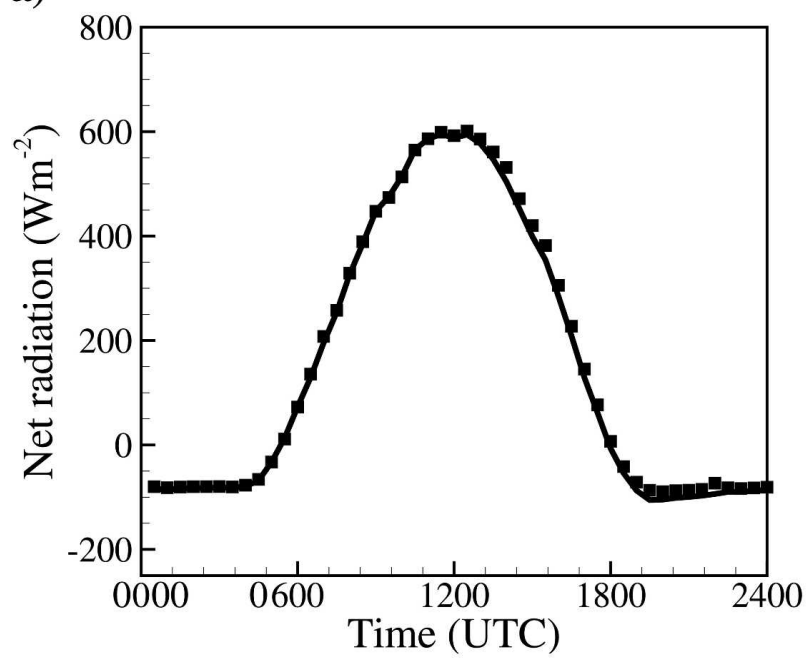

c)

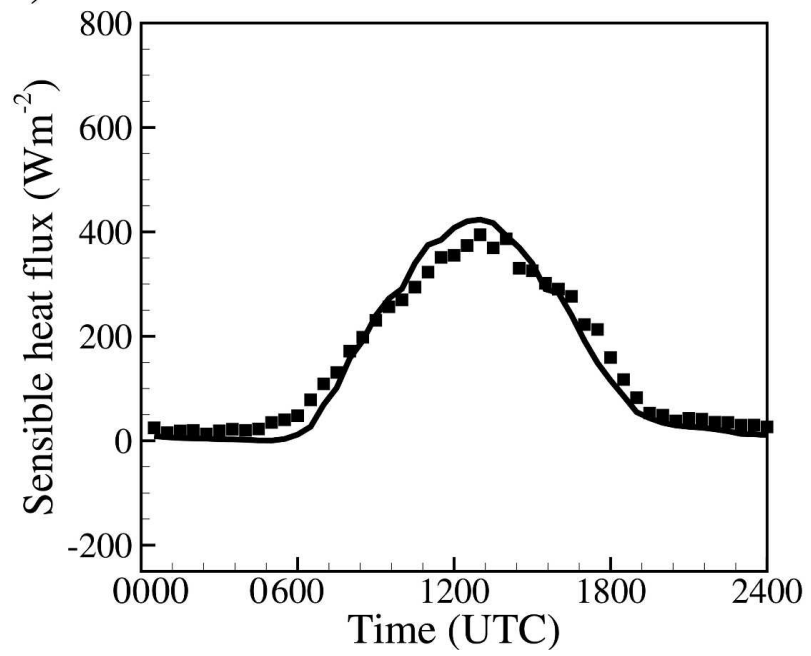

b)

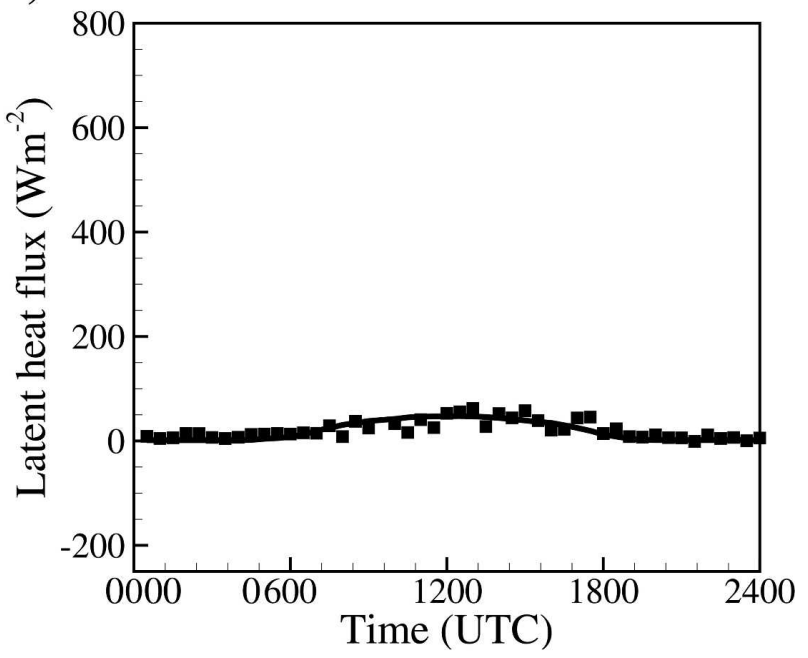

d)

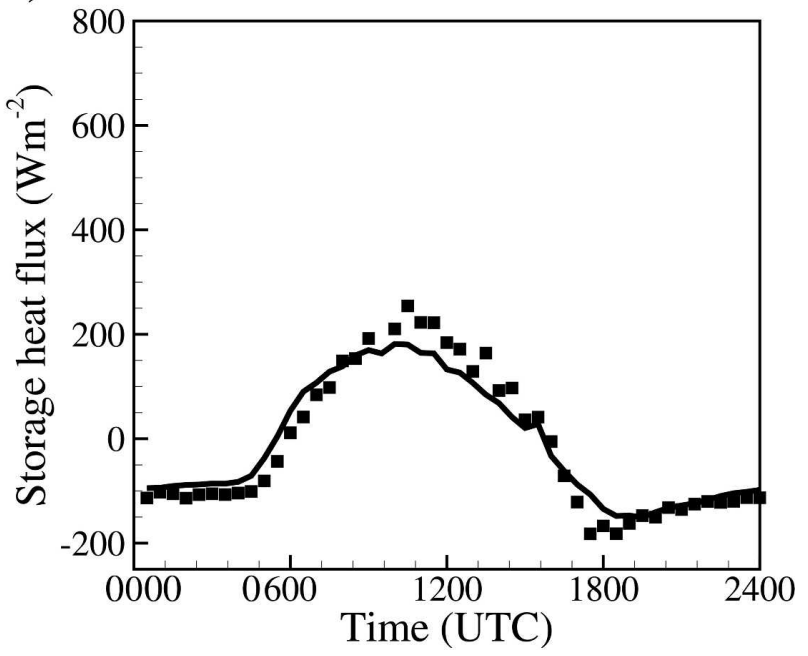

FIG. 3. Comparison on an average diurnal cycle between observed (dots) and simulated (solid line) (a) net radiation, (b) latent heat flux, (c) sensible heat flux, and (d) storage heat flux.

Fig. 3 that the early morning sensible heat flux underestimation is exactly compensated by the storage heat flux overestimation; but which is the cause and which the effect?

Despite the large values of the latent heat flux rmse, SM2-U appears to be able to simulate the main characteristics of the energy budget of the Marseille downtown core: the average pattern of the heat fluxes are accurately simulated with small rmse values for the radiative fluxes and there are reasonable simulations for the sensible heat flux. A large fraction of these rmse is due to unsystematic errors. The rmse fraction of systematic errors is larger during the night, maybe because of an underestimation of the surface temperature and/ or of the anthropogenic heat fluxes. The comparison with TEB performances in the Lemonsu et al. (2004) study (Fig. 4b) shows that the two models produce the same quality of results. SM2-U better simulates the net radiation with an rmse of $21 \mathrm{~W} \mathrm{~m}^{-2}$ against $30 \mathrm{~W} \mathrm{~m}^{-2}$ for TEB. The sensible and storage heat flux rmse of the two models are very close for the overall period, while TEB is slightly better during daytime. This comparison indicates that the results may be equivalent although SM2-U has a much simpler representation of the urban canopy.

\section{2) InStANTANEOUS FLUXES OVER A 14-DAY PERIOD}

Lemonsu et al. (2004) and Grimmond et al. (2004) classified Marseille meteorological conditions during 

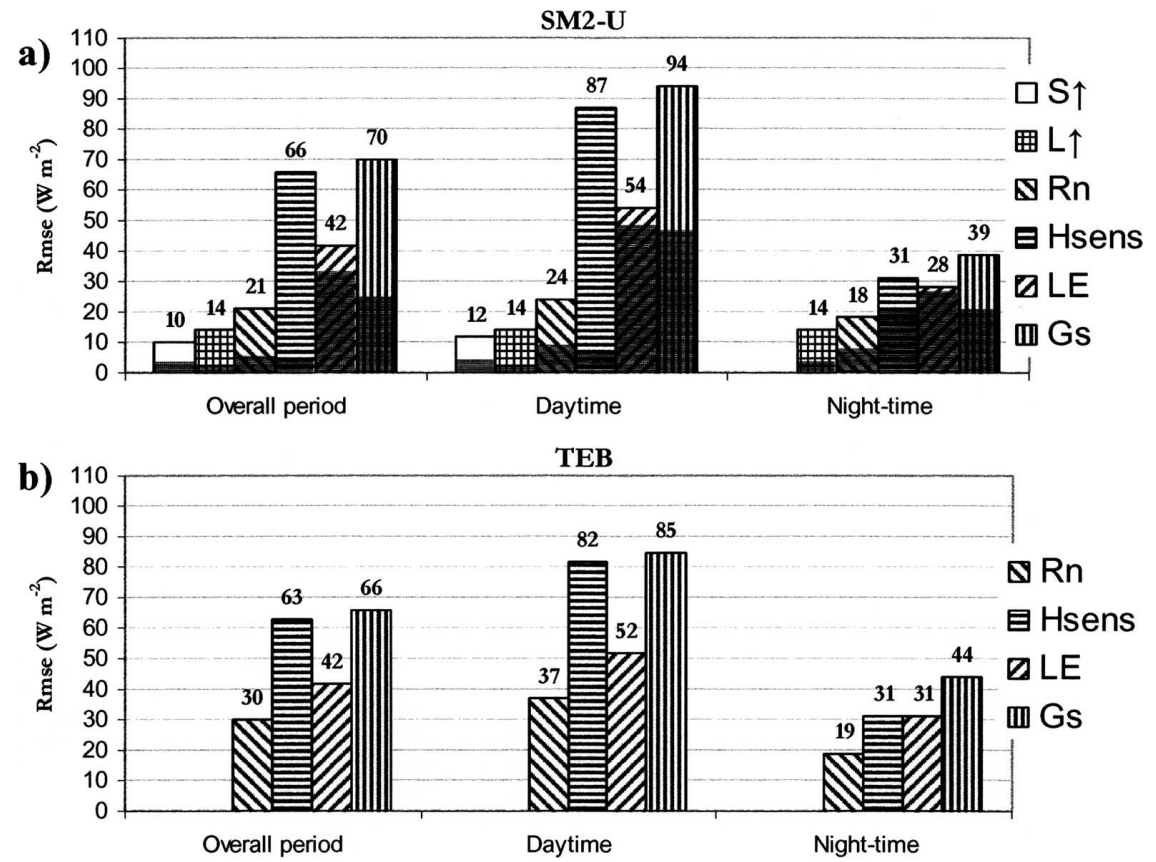

FIG. 4. Rmse obtained by (a) SM2-U and (b) TEB on the energy fluxes for the overall, daytime, and nighttime periods. The fluxes are the outgoing shortwave radiation $(S \uparrow)$, the outgoing longwave radiation $(L \uparrow)$, the net radiation $\left(R_{n}\right)$, the sensible heat flux $\left(H_{\text {sens }}\right)$, the latent heat flux (LE), and the storage heat flux $\left(G_{s}\right)$. The shaded areas are the systematic error fractions (rmse).

the observation period into three wind regimes (Lemonsu et al. 2004; Grimmond et al. 2004), "mistral", "sea/ land breeze," and "other," which correspond to different fetch conditions of turbulent flux measurements. The mistral is a strong northwest wind, whereas the breezes are light-to-moderate winds from the northwest, southwest, or southeast. Lemonsu et al. (2004) showed that the dynamic variation of the source areas of the turbulent heat fluxes according to these three wind regimes has a limited impact on the simulated heat fluxes because of the relative homogeneity of the Marseille city center surface characteristics. To differentiate the model performances for the three wind regimes, Fig. 5 compares the instantaneous simulated fluxes with observations over a 14-day period, with the indication of wind regimes: " $\mathrm{M}$ " for mistral, " $\mathrm{B}$ " for the sea/land breeze regime, and "O" for other ill-identified regimes. As expected the model simulates the net radiation for all wind regimes with the same accuracy. The sensible heat flux is also well simulated in general, but the performances of the model seem better under mistral (days 169, 170, 179, and 182) and other (day 171) wind regimes than under the breeze regime when measurements show a high hourly variability. This observation is even more evident for the latent heat flux where the measured fluxes are characterized by sudden short-term positive and negative excursions during the breeze regime (Grimmond et al. 2004) while the simulation shows a quiet behavior. Because the measured sensible heat fluxes do not show similar strong shortterm excursions (with clear negative values), they are not produced by an unusual behavior of the vertical wind component. This high hourly variability explains the large rmse for the overall period (Fig. 4a). The more stable flux measurements observed during mistral regime is attributed by Grimmond et al. (2004) to the spatial and temporal consistency of the mistral wind and the enhanced mixing from their direction. Because the authors of the measurements do not question their accuracy [although the intercomparison of flux instruments showed large variabilities, see Mestayer et al. (2005)], a large part of the variability in the measurements and in the model-observation difference may be attributed to nonlocal influences. While the model computes the fluxes generated by transfers from an average theoretical footprint, measurements are influenced also by larger-scale advections. Pigeon et al. (2003) showed that the divergence terms in the energy budget equations, which are due to the spatial inhomogeneity of the city, to the height difference between the canopy surface and the mast sensors, and to the temporal instationnarity, and are neglected in the basic Eq. 


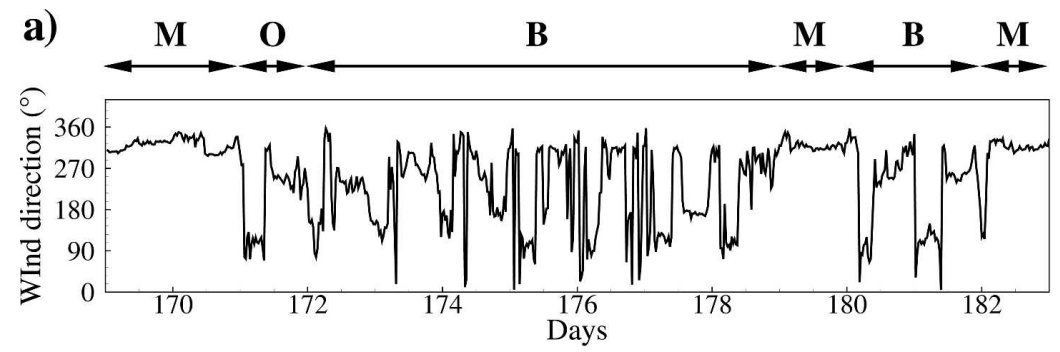

b)

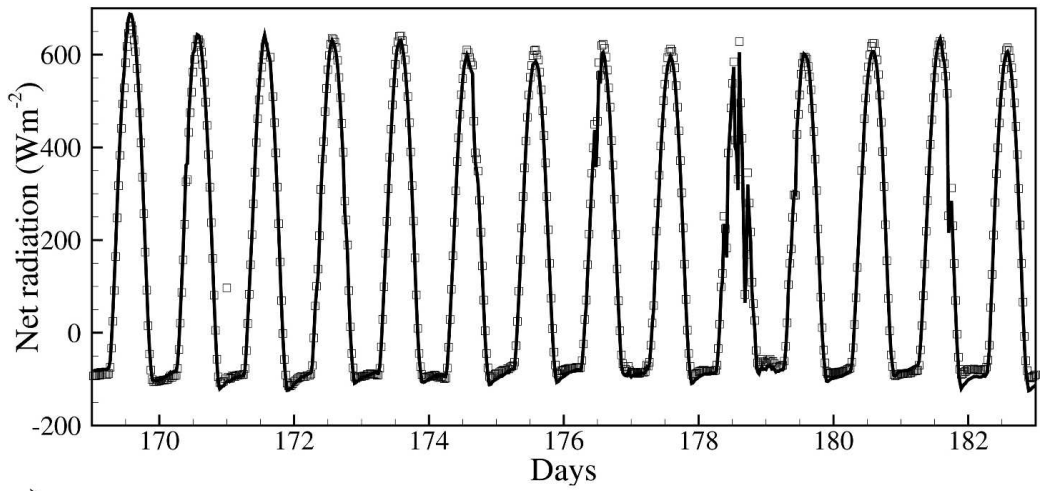

c)

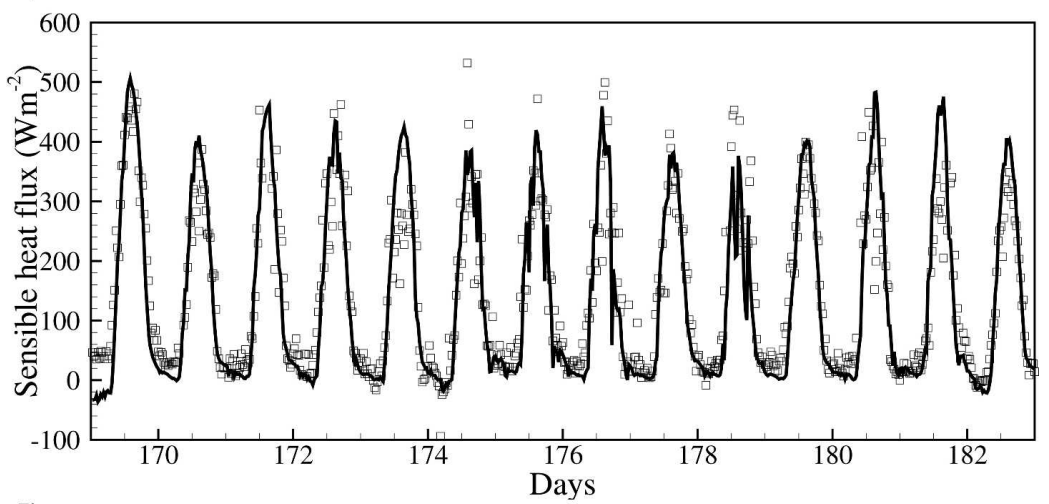

d)

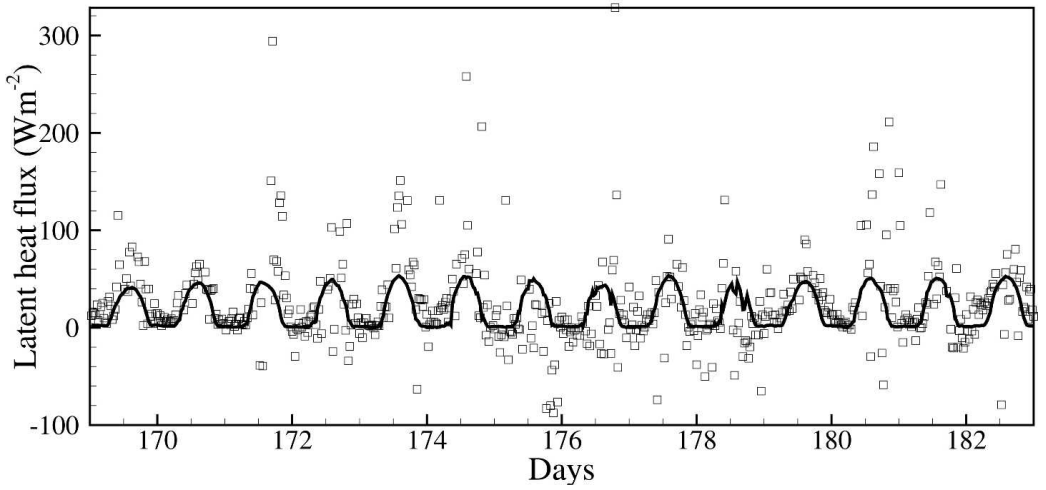

FIG. 5. Comparison of the simulated (solid line) and observed (dots) 1-h (b) net radiation, (c) sensible heat flux, and (d) latent heat flux for a representative 14-day period. (a) The measured wind direction with the three wind regimes: mistral (M), sea-land breeze (B), and others (O) are shown. 

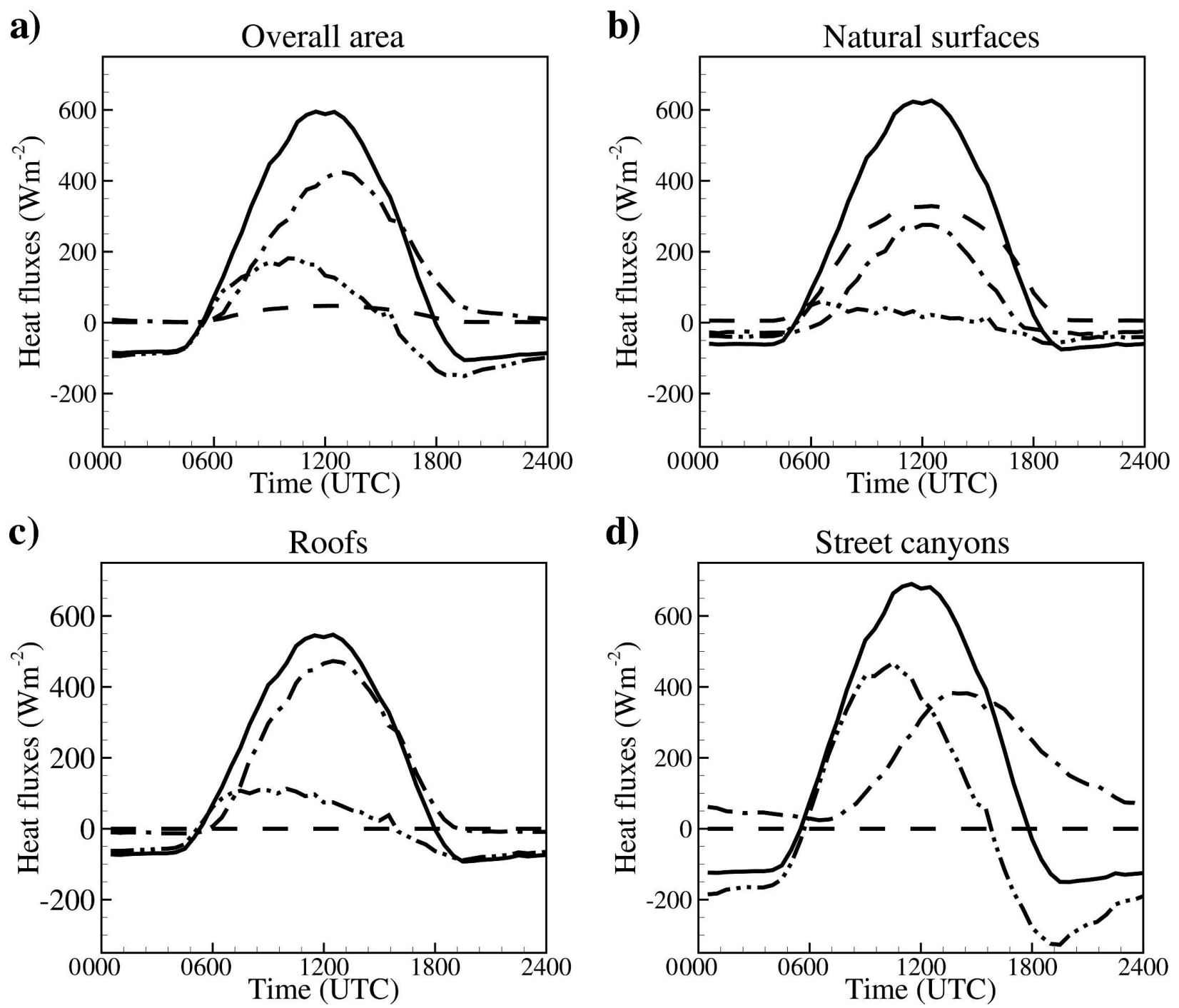

FIG. 6. Average simulated energy budgets of Marseille city center for (a) the overall area, (b) natural surfaces, (c) roofs, and (d) paved surfaces. Solid line: net radiation flux; dashed line: latent heat flux; dash-dot line: sensible heat flux; dash-dot-dot line: storage heat flux.

(1), do influence the measured and modeled fluxes differently. Here the differences appear mainly in the latent heat fluxes because of their low magnitudes in general and because of the strong contrast between the humid air that is advected from the sea surface and the very dry air that is advected from the city and from the bare ground surfaces of the hills in summer. In these conditions, a "dynamic footprint" approach, where the footprint is adjusted to the wind conditions at a short time scale, would not be sufficient to improve the simulations, and a full coupling with an atmospheric model may be necessary to take into account larger-scale advection.

\section{Surface energy budgets simulated by SM2-U}

\section{a. Average diurnal cycles}

The 21-day average pattern of the simulated energy budget diurnal cycles (Fig. 6a) is typical of a dense urban canopy. The latent heat flux is small because of the low rate of natural surfaces. It reaches a maximum value of $50 \mathrm{~W} \mathrm{~m}^{-2}$. A large part of the net radiation is stored by artificial surfaces during the morning. Actually, all of the available radiative energy is converted into stored heat during the first hour after sunrise. However, the maximum value of the storage heat flux is lower than that of the sensible heat flux, unlike that 


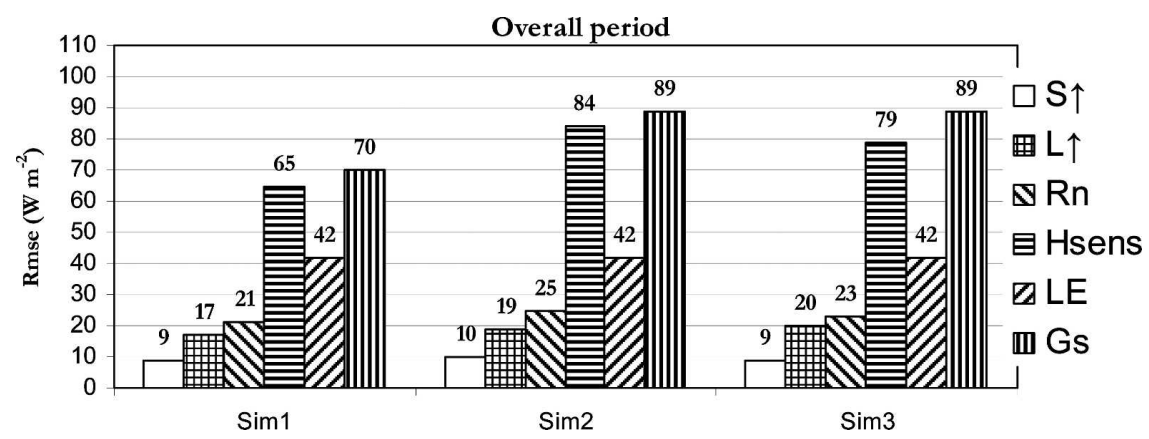

FIG. 7. Rmse of the simulated heat fluxes for the overall period, for the three alternative simulations.

observed by Grimmond and Oke (1999) in Mexico City. The storage heat flux grows rapidly in the morning and reaches its maximum $2 \mathrm{~h}$ earlier than the net radiation flux. Conversely, the sensible heat flux morning growth is hampered by this energy inveigling and it reaches its maximum $1 \mathrm{~h}$ later than the net radiation, after noon, illustrating well the "hysteresis" observed by Grimmond and Oke (1999) in American cities. The stored heat is then released to the atmosphere during the late afternoon and night, slowing down the surface cooling, inducing a positive sensible heat flux, and contributing to the urban heat island main component, as observed in the spatial distribution of canopy temperature (Mestayer et al. 2005; Long et al. 2003).

The model simulation allows observation of the energy budgets of natural surfaces, roofs, and street canyons (Figs. 6b-d) separately. The roof energy budget is characterized by a large sensible heat flux during the day and by relatively low heat storage, insufficient to induce a positive nocturnal sensible heat flux. This is due to the large percentage of traditional buildings in Marseille old core, whose roofs are covered with "roman" tiles over a relatively thick, insulated attic. Although the surface temperature diurnal cycle has a large amplitude during sunny days with clear sky, the thin layer of tiles does not store much heat while the attic insulates well the bulk of the house. The large storage heat flux of the overall area is essentially due to the street canyons as shown by Fig. 6d. This energy budget is characterized by a very large daytime storage heat flux, higher than the sensible heat flux, and a large nocturnal heat release contributing to a positive sensible heat flux. The energy budgets of the two artificial surfaces differ largely. The much larger storage heat flux of the streets results from a large heat capacity of the walls but also from an enhanced radiation capture. The increased surface ratio per unit area resulting from the folded surface, the low pavement albedo, and the lower effective albedo of narrow streets explain the larger daytime net radiation of the streets. At night the negative radiation flux is also larger over the streets because of the larger area ratio. The roof sensible heat flux falls to zero at night because of the thin tile layer rapid temperature adjustment to equilibrium with air, and the negative net radiation is balanced by the extracted heat flux cooling the building interior.

As expected, the simulated daytime energy budget of natural surfaces is characterized by a large latent heat flux, higher than the sensible heat flux, and by a small storage heat flux. The latent heat flux is especially due to the vegetation transpiration. The nocturnal sensible heat flux is negative.

\section{b. Sensitivity study to urban canopy representation}

Three additional simulations have been performed to assess the impact of the building heat transfer/storage process modeling. The reference simulation $\operatorname{sim} 0$ is that of the previous section. In the first new simulation (sim1) the effective albedo and emissivities of the street canyon are replaced by those of the street canyon floor as if the presence of the walls had no influence on the radiative budget, that is, $\alpha_{\text {pav }}^{\text {eff }}, \varepsilon_{\text {pav }}^{\text {Aeff }}$, and $\varepsilon_{\text {pav }}^{\text {IReff }}$ are equal to the asphalt albedo and emissivity. In the second new simulation $(\operatorname{sim} 2)$ the heat transfers through the artificial surfaces (roofs, walls, and pavement) are computed with only one layer aggregating the two layers of $\operatorname{sim} 0$ ( $s$ and 2). The third simulation (sim3) is performed without the walls $(H / W=0)$, which corresponds to the flat-city approach of the simulations by an "adapted" bare ground.

For the overall period the flux rmse values obtained in these three new simulations are presented in Fig. 7. The replacement of the street canyon effective albedo and emissivities by those of the pavement (sim1) does not change strongly the results and the rmse values are nearly the same in sim 1 and sim0 (see Fig. 4a), with only a small increase in the rmse of $L \uparrow$. The flux mean diurnal cycles are very close to those of $\operatorname{sim} 0$ (Figs. $8 \mathrm{a}$ 

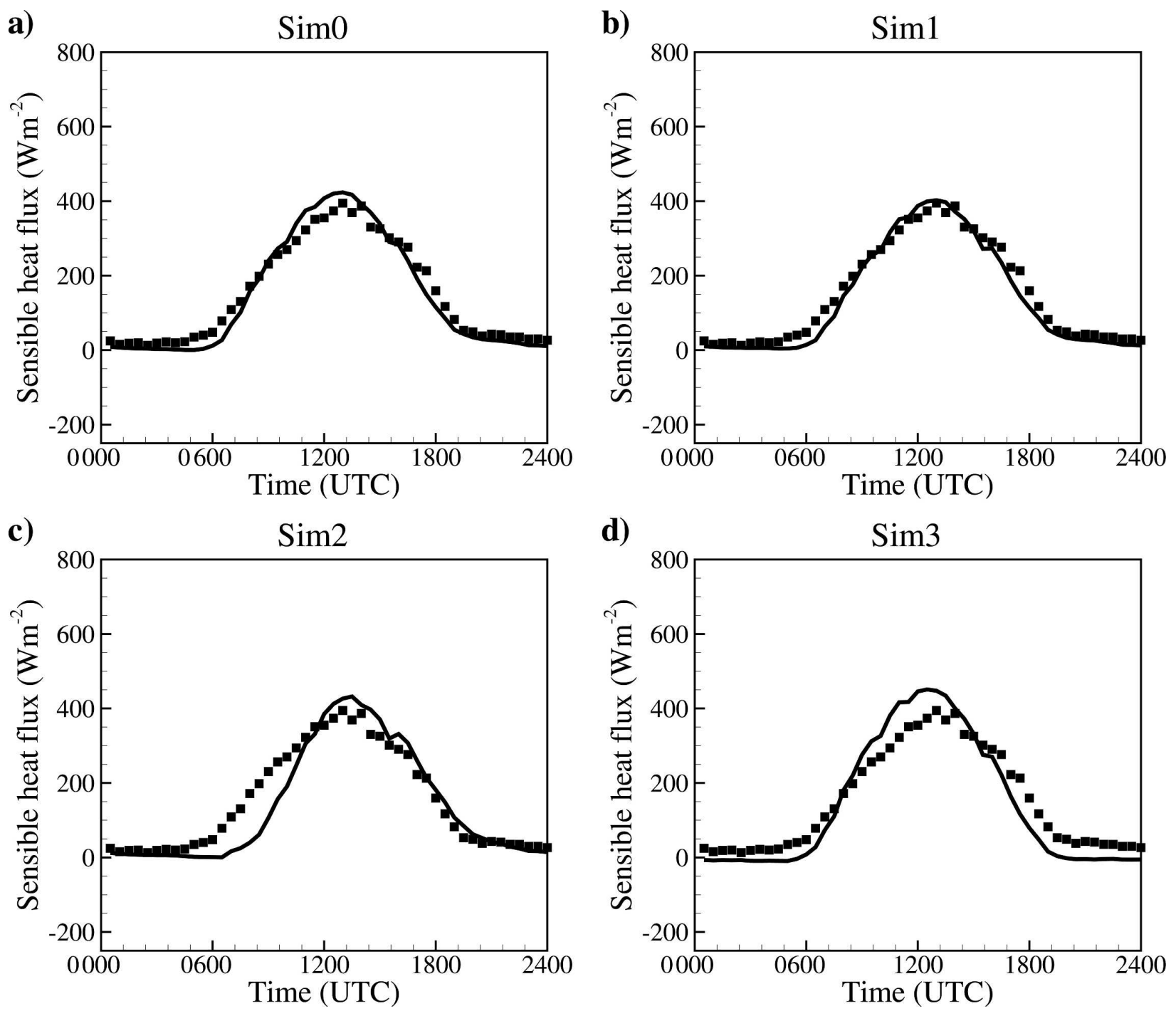

FIG. 8. Comparison of observed (dots) and simulated (solid line) average sensible heat flux diurnal cycle for the alternative simulations (a) sim0, (b) sim1, (c) $\operatorname{sim} 2$, and (d) $\operatorname{sim} 3$.

and $8 \mathrm{~b}$ ), but the net radiation is slightly lower during the day because of the larger albedo; the pavement albedo is 0.08 whereas the midday effective albedo is about 0.04 in $\operatorname{sim} 0$. The replacement of the effective emissivities [in $\operatorname{sim} 0, \varepsilon_{\mathrm{pav}}^{\text {Aeff }}=0.97$ and $\varepsilon_{\mathrm{pav}}^{\text {IReff }}=0.99$ from Eqs. (A17) and (A18), respectively] by the asphalt emissivity (0.94) does not seem to have a large impact on the results: on the one side it decreases the atmospheric radiations absorbed by the street canyon surfaces whereas on the other side it increases the infrared radiation emission.

In $\operatorname{sim} 2$, where artificial surfaces are modeled with only one material layer, the sensible and storage heat fluxes are not simulated as well as with the two layers of the reference simulation $\operatorname{sim} 0$, and the sensible heat flux rmse attains $84 \mathrm{~W} \mathrm{~m}^{-2}$ as compared with $66 \mathrm{~W} \mathrm{~m}^{-2}$ in sim0. The other fluxes have about the same rmse in $\operatorname{sim} 0$ and $\operatorname{sim} 2$. The impact on the energy budget of the two-layer modeling is evidenced by the comparison of $\operatorname{sim} 2$ and $\operatorname{sim} 0$ sensible heat flux mean diurnal cycles (Figs. 8a and 8c). The major difference appears in the 5 $\mathrm{h}$ following sunrise. With the unique layer aggregating the two layers in sim0, the model does not reproduce the morning release of sensible heat by artificial surfaces well because the layer is too thick, with a large heat capacity, impeding the model's ability to respond rapidly to environmental forcing variations: the storage/release process is too slow. On the other hand, if the simulation is repeated with a unique layer having the same thickness as the first layer of $\operatorname{sim} 0$ (not shown here), the model does respond rapidly to the forcing variations, but it does not simulate well the heat storage 
in the artificial materials because this layer is too thin, and its behavior is similar to that of the roofs in Fig. 6c. Thus, representing artificial surface materials with two layers appears as a necessary compromise where the first thin layer allows the model fast response, and the second layer ensures the storage capacity. Some models, like TEB, represent the walls with up to four layers where the third one (starting from the outside) is generally an insulating layer limiting the heat transfer between the second layer and the fourth inner layer; its effect is actually well represented in SM2-U by means of the heat transfer coefficient $K_{i}$.

When walls are not accounted for $(\operatorname{sim} 3)$ sensible heat fluxes are much less well simulated than in $\operatorname{sim} 0$, and the rmse reaches 79 instead of $66 \mathrm{~W} \mathrm{~m}^{-2}$ (cf. Figs. 7 and $4 a$ ). The main influence of walls on the energy budget is in the canopy heat storage capacity; without walls, the stored heat is smaller during the day, which results in a larger midday sensible heat flux (Fig. 8d) and a smaller nocturnal heat release, inducing a negative nocturnal sensible heat flux.

This small sensitivity study shows that an accurate modeling of heat transfers in walls, including the fast response to environmental forcing variations and the heat storage capacity, is essential for obtaining a correct diurnal cycle of heat fluxes to the UBL. Modeling the influence of building walls can be easily performed with a modified paved surface equation. The quality of the results appears to depend much more on the modeling of heat transfers and storage in walls than on the effective albedo and emissivities. Thus, more complex parameterizations of the radiative trapping do not appear necessary, at least for these Marseille city center simulations; the mere replacement of the street canyon effective albedo and emissivities by the pavement values does not degrade the heat flux simulation performances largely. This confirms one of the conclusions of Kusaka and Kimura's (2004) model sensitivity study - that the impact of albedo modeling is not as large as the other factors.

\section{Conclusions}

The SM2-U soil model has been developed as an urban extension of the ISBA model of Noilhan and Planton (1989) with the primary purpose of computing the instantaneous energy budget and fluxes at the urban canopy-atmosphere interface for the lower boundary condition of high-resolution atmospheric models. Unlike the current urban schemes, SM2-U models rural and urban soils altogether without transitions, allowing for continuous simulation of all of the intermediate parts of an urban area between the natural surroundings and the city center. It integrates in a simple way the physical processes of the urban canopy such as heat exchanges, heat storage, radiative trapping, water interception, and surface water runoff. The building wall energy budget is not computed explicitly and separately, avoiding questionable parameterizations of the wind velocity inside the canopy. The urban canopy thickness influence is integrated within a modified set of the equations for the paved surface energy budget and temperature, which includes 1) the radiative trapping in the parameterizations of effective street canyon albedo and emissivities, 2) the fast reactivity of artificial materials to atmospheric forcing in the thin superficial layer of the budget equation, and 3) the large heat storage capacity of building walls in the heat transfer equation between the wall superficial and inner layers. Thus, for the densely urbanized districts the paved surface energy budget corresponds to the energy budget at the top of an average street canyon, while the canyon influence decreases with the decreasing building height and density.

The SM2-U model has been evaluated without soilatmosphere feedback on the downtown core of Marseille against heat flux measurements collected during the 2001 UBL-ESCOMPTE campaign (Grimmond et al. 2004). The main features of the energy budget of the Marseille city center are well reproduced, and the average pattern of the heat fluxes are accurately simulated with small root-mean square errors for the radiative fluxes and reasonable ones for the sensible heat flux. A large fraction of these rmse is due to unsystematic errors. However, the systematic error fractions are larger during the night, maybe due to a small but systematic model underestimation of the surface temperature or to an underevaluated anthropogenic heat flux of Marseille. The comparison with Lemonsu et al.'s (2004) results obtained with the detailed urban TEB scheme shows similar rmse values indicating similar modeling performances. This suggests that the detailed, separate calculations of the complete radiative trapping and of multiple-layer wall energy budgets are not necessary and that the wall influence is sufficiently well modeled when integrated in the modified paved surface equations. On the other hand, the sensitivity study to canopy (walls and roofs) parameterizations shows that they are essential to obtain the instantaneous fluxes and surface temperatures; especially important are the accurate account of wall area and the two-layer parameterization of heat transfers in the artificial materials that renders both the fast response to environmental forcing variations and the large heat storage capacity. The heat transfer/storage parameterizations appear to have more importance in the urban energy budget calculation than the computation of the effective albedo and emissivities; for example, the replacement of the street effective 
albedo and emissivities by the pavement values largely did not change the simulated heat fluxes. Hence complete, explicit computations of the radiative trapping may not be necessary for obtaining heat fluxes.

Acknowledgments. Dr. Isabelle Calmet is gratefully acknowledged for her help.

\section{APPENDIX}

\section{Parameterization of the Effective Albedo and Emissivities of a Street Canyon}

This appendix presents the SM2-U parameterization of the effective albedo and emissivities for evaluating the net radiation flux at the top of the street canyon. It is partly adapted from Masson (2000) and Lemonsu et al. (2004).

\section{a. Effective albedo}

The direct solar radiation $S_{\text {pav }}^{* \Downarrow}$ absorbed after an infinite number of reflections by any surface of a street canyon is deduced from

$$
S_{\mathrm{pav}}^{*}=P_{f} S_{f}^{\Downarrow}+P_{w} S_{w}^{\Downarrow}
$$

where the indices $f$ and $w$ reference the floor (pavement) and the walls, respectively, and with

$$
\begin{aligned}
P_{f}= & \left(1-\alpha_{f}\right)+\frac{\alpha_{f}\left[\left(1-\alpha_{f}\right)\left(1-\psi_{f \rightarrow s}\right) \psi_{w \rightarrow s} \alpha_{w}+\frac{2 H}{W}\left(1-\alpha_{w}\right) \psi_{w \rightarrow s}\right]}{1-\left(1-2 \psi_{w \rightarrow s}\right) \alpha_{w}-\left(1-\psi_{f \rightarrow s}\right) \alpha_{f} \alpha_{w} \psi_{w \rightarrow s}}, \\
P_{w}= & \frac{2 H}{W}\left(1-\alpha_{w}\right)+\frac{\alpha_{w}\left[\left(1-\alpha_{f}\right)\left(1-\psi_{f \rightarrow s}\right)+\frac{2 H}{W}\left(1-\alpha_{w}\right)\left(1-2 \psi_{w \rightarrow s}\right)+\frac{2 H}{W}\left(1-\alpha_{w}\right)\left(1-\psi_{f \rightarrow s}\right) \psi_{w \rightarrow s} \alpha_{f}\right]}{1-\left(1-2 \psi_{w \rightarrow s}\right) \alpha_{w}-\left(1-\psi_{f \rightarrow s}\right) \alpha_{f} \alpha_{w} \psi_{w \rightarrow s}}, \\
\psi_{f \rightarrow s}= & {\left[\left(\frac{H}{W}\right)^{2}+1\right]^{1 / 2}-\frac{H}{W}, \quad \text { and } } \\
\psi_{w \rightarrow s}= & \frac{1}{2}\left\{\frac{H}{W}+1-\left[\left(\frac{H}{W}\right)^{2}+1\right]^{1 / 2}\right\}\left(\frac{H}{W}\right)^{-1},
\end{aligned}
$$

where $S^{\Downarrow}$ represents the direct solar radiation received by the considered surface $\left(\mathrm{W} \mathrm{m}^{-2}\right) ; \alpha$ is the surface albedo; $\psi_{f \rightarrow s}$ and $\psi_{w \rightarrow s}$ are the sky-view factors of the street floor and of one wall, respectively; and $H$ and $W$ are, respectively, the height and width of the street canyon $(\mathrm{m})$.

Equation (A1) can be rewritten in the following form:

$$
S_{\mathrm{pav}}^{*}=\left(Q_{r} P_{r}+Q_{w} P_{w}\right) S_{\mathrm{pav}}^{\Downarrow}=\left(1-\alpha_{\mathrm{eff}}^{\Downarrow}\right) S_{\mathrm{pav}}^{\Downarrow},
$$

where $\alpha_{\text {eff }}^{\Downarrow}$ is the effective albedo for the direct solar radiation, and $S_{\text {pav }}^{\Downarrow}$ is the direct solar radiation at the canopy-top level $\left(\mathrm{W} \mathrm{m}^{-2}\right)$.

If it is assumed that all canyon orientations in a computational cell are possible, as done for the model validation on the Marseille city center, then

$$
\begin{gathered}
Q_{w}=\left[\frac{W}{H}\left(\frac{1}{2}-\frac{\theta_{c 0}}{\pi}\right)+\frac{1}{\pi} \tan Z_{e}\left(1-\cos \theta_{c 0}\right)\right] \text { and } \\
Q_{f}=\left[\frac{2 \theta_{c 0}}{\pi}-\frac{2}{\pi} \frac{H}{W} \tan Z_{e}\left(1-\cos \theta_{c 0}\right)\right],
\end{gathered}
$$

with

$$
\theta_{c 0}=\arcsin \left[\min \left(\frac{W}{H} \frac{1}{\tan Z_{e}} ; 1\right)\right],
$$

where $Z_{e}$ is the solar zenith angle (rad) and $\theta_{c 0}$ is the critical canyon orientation for which the floor is no longer in the sunlight (rad).

On the contrary, if a mean dominant street orientation per computational cell is assumed:

$$
Q_{w}=\left\{\begin{array}{l}
\frac{1}{2} \frac{W}{H} \text { for } \theta_{c}>\theta_{c 0} \quad \text { (the floor is not in the sunlight) } \\
\frac{1}{2} \tan Z_{e} \sin \theta_{c} \text { for } \theta_{c}<\theta_{c 0} \quad \text { (the floor is in the sunlight) }
\end{array}\right.
$$


and

$$
Q_{f}=\left\{\begin{array}{l}
0 \text { for } \theta_{c}>\theta_{c 0} \\
1-\frac{H}{W} \tan Z_{e} \sin \theta_{c} \text { for } \theta_{c}<\theta_{c 0},
\end{array}\right.
$$

where $\theta_{c}$ is the angle between the sun direction and the direction at $\pi / 2$ from the canyon axis (rad).

The street canyon effective albedo for the direct solar radiation is thus equal to

$$
\alpha_{\text {eff }}^{\Downarrow}=1-Q_{f} P_{f}-Q_{w} P_{w} .
$$

The scattered solar radiation $S_{\text {pav }}^{* \downarrow}$ absorbed after an infinite number of reflections by the street surfaces is deduced from

$$
S_{\text {pav }}^{* \downarrow}=P_{f} S_{f}^{\downarrow}+P_{w} S_{w}^{\downarrow},
$$

where $S^{\downarrow}$ represents the scattered solar radiation (W $\mathrm{m}^{-2}$ ) absorbed by any surface.

Equation (A13) can be rewritten in the following form:

$$
S_{\mathrm{pav}}^{* \downarrow}=\left(\psi_{f \rightarrow s} P_{f}+\frac{W}{H} \psi_{w \rightarrow s} P_{w}\right) S_{\mathrm{pav}}^{\downarrow}=\left(1-\alpha_{\mathrm{eff}}^{\downarrow}\right) S_{\mathrm{pav}}^{\downarrow},
$$

where $\alpha_{\text {eff }}^{\downarrow}$ is the effective albedo for the scattered solar radiation, and $S_{\mathrm{pav}}^{\downarrow}$ is the scattered solar radiation at the canyon top level $\left(\mathrm{W} \mathrm{m}^{-2}\right)$.

The effective albedo for the scattered solar radiation is thus equal to

$$
\alpha_{\mathrm{eff}}^{\downarrow}=1-\psi_{f \rightarrow s} P_{f}-\frac{W}{H} \psi_{w \rightarrow s} P_{w} .
$$

For clear-sky days, the direct solar radiation being much larger than the scattered solar radiation, which represents approximately $15 \%$ of the global solar radiation according to Guyot (1997), it is assumed in SM2-U that the effective albedo of the street canyon $\alpha_{\mathrm{pav}}^{\mathrm{eff}}$ for the global solar radiation is equal to that for the direct solar radiation, such that

$$
\alpha_{\mathrm{pav}}^{\mathrm{eff}}=\alpha_{\mathrm{eff}}^{\Downarrow}
$$

\section{b. Effective emissivities}

The effective emissivites of the street canyon for the atmospheric radiation absorption term $\varepsilon_{\mathrm{pav}}^{\text {Aeff }}$ and the infrared emission term $\varepsilon_{\text {pav }}^{\text {IReff }}$ are calculated by considering only one reflection of the atmospheric and infrared radiations. Thus,

$$
\begin{aligned}
\varepsilon_{\text {pav }}^{\text {Aeff }}= & \varepsilon_{\text {pav }} \psi_{f \rightarrow s}+\varepsilon_{\text {pav }}\left(1-\varepsilon_{\text {wall }}\right)\left(1-\psi_{f \rightarrow s}\right) \psi_{w \rightarrow s}+2 \frac{H}{W}\left[\varepsilon_{\text {wall }} \psi_{w \rightarrow s}+\varepsilon_{\text {wall }}\left(1-\varepsilon_{\text {pav }}\right) \psi_{w \rightarrow s} \psi_{f \rightarrow s}\right. \\
& \left.+\varepsilon_{\text {wall }}\left(1-\varepsilon_{\text {wall }}\right) \psi_{w \rightarrow s}\left(1-2 \psi_{w \rightarrow s}\right)\right]
\end{aligned}
$$

and

$$
\begin{aligned}
\varepsilon_{\mathrm{pav}}^{\mathrm{IReff}}= & \varepsilon_{\mathrm{pav}}-\varepsilon_{\mathrm{pav}} \varepsilon_{\mathrm{wall}}\left(1-\psi_{f \rightarrow s}\right)-\varepsilon_{\mathrm{pav}} \varepsilon_{\mathrm{wall}}\left(1-\varepsilon_{\mathrm{wall}}\right)\left(1-\psi_{f \rightarrow s}\right)\left(1-2 \psi_{w \rightarrow s}\right)-\varepsilon_{\mathrm{pav}}^{2}\left(1-\varepsilon_{\mathrm{wall}}\right)\left(1-\psi_{f \rightarrow s}\right) \psi_{w \rightarrow s} \\
& +2 \frac{H}{W}\left[\varepsilon_{\mathrm{wall}}-\varepsilon_{\mathrm{wall}} \varepsilon_{\mathrm{pav}} \psi_{w \rightarrow s}-\varepsilon_{\mathrm{wall}}^{2}\left(1-2 \psi_{w \rightarrow s}\right)-\varepsilon_{\text {wall }}^{2}\left(1-\varepsilon_{\text {wall }}\right)\left(1-2 \psi_{w \rightarrow s}\right)^{2}\right. \\
& \left.-\varepsilon_{\mathrm{wall}}^{2}\left(1-\varepsilon_{\mathrm{pav}}\right) \psi_{w \rightarrow s}\left(1-\psi_{f \rightarrow s}\right)-\varepsilon_{\mathrm{wall}} \varepsilon_{\mathrm{pav}}\left(1-\varepsilon_{\mathrm{wall}}\right) \psi_{w \rightarrow s}\left(1-2 \psi_{w \rightarrow s}\right)\right],
\end{aligned}
$$

where $\varepsilon_{\text {wall }}$ and $\varepsilon_{\text {pav }}$ are, respectively, the emissivities of the wall and of the street canyon floor (pavement).

\section{REFERENCES}

Barlow, J. F., and S. E. Belcher, 2002: A wind tunnel model for quantifying fluxes in the urban boundary layer. Bound.-Layer Meteor., 104, 131-150.

Beljaars, A. C. M., and A. A. M. Holtslag, 1991: Flux parameterization over land surfaces for atmospheric models. J. Appl. Meteor., 30, 327-341.

Best, M. J., 2005: Representing urban areas within operational numerical weather prediction models. Bound.-Layer Meteor., 114, 91-109.
Boone, A., J.-C. Calvet, and J. Noilhan, 1999: Inclusion of a third soil layer in a land surface scheme using the force-restore method. J. Appl. Meteor., 38, 1611-1630.

Byun, D. W., 1990: On the analytical solutions of flux-profile relationships for the atmospheric surface layer. J. Appl. Meteor., 29, 652-657.

Ca, V. T., Y. Ashie, and T. Asaeda, 2002: A $k-\varepsilon$ turbulence closure model for the atmospheric boundary layer including urban canopy. Bound.-Layer Meteor., 102, 459-490.

Chen, F., Z. Janjic, and K. Mitchell, 1997: Impact of atmospheric surface-layer parameterizations in the new land-surface scheme of the NCEP Mesoscale Eta Model. Bound.-Layer Meteor., 85, 391-421.

Cros, B., and Coauthors, 2004: The ESCOMPTE program: An overview. Atmos. Res., 69, 241-279. 
De Ridder, K., and G. Schayes, 1997: The IAGL land surface model. J. Appl. Meteor., 36, 167-182.

Dupont, S., 2001: Modélisation dynamique et thermodynamique de la canopée urbaine: Réalisation du modèle de sols urbains pour SUBMESO (Dynamics and thermodynamics modeling of the urban canopy: Development of an urban soil model for SUBMESO). Doctoral thesis, Université de Nantes, 319 pp.

— I. Calmet, and P. G. Mestayer, 2002: Urban canopy modeling influence on urban boundary layer simulation. Proc. 4th Symp. on Urban Environment, Norfolk, VA, Amer. Meteor. Soc., 151-152.

— , T. L. Otte, and J. K. S. Ching, 2004: Simulation of meteorological fields within and above urban and rural canopies with a mesoscale model (MM5). Bound.-Layer Meteor., 113, 111-158.

, P. G. Mestayer, E. Guilloteau, E. Berthier, and H. Andrieu, 2006: Parameterization of the urban water budget with the submesoscale soil model. J. Appl. Meteor. Climatol., 45, 624648.

Giordani, H., J. Noilhan, P. Lacarrere, P. Bessemoulin, and P. Mascart, 1996: Modelling the surface processes and the atmospheric boundary layer for semi-arid conditions. Agric. For. Meteor., 80, 263-287.

Grimmond, C. S. B., and T. R. Oke, 1999: Heat storage in urban areas: Local-scale observations and evaluation of a simple model. J. Appl. Meteor., 38, 922-940.

$\longrightarrow$, and - 2002: Turbulent heat fluxes in urban areas: Observations and a Local-Scale Urban Meteorological Parameterization Scheme (LUMPS). J. Appl. Meteor., 41, 792-810.

— , J. A. Salmond, T. R. Oke, B. Offerle, and A. Lemonsu, 2004: Flux and turbulence measurements at a densely builtup site in Marseille: Heat, mass (water and carbon dioxide), and momentum. J. Geophys. Res., 109, D24101, doi:10.1029/ 2004JD004936.

Guilloteau, E., 1998: Optimized computation of transfer coefficients in surface layer with different momentum and heat roughness lengths. Bound.-Layer Meteor., 87, 147-160.

_ 1999: Modélisation des sols urbains pour les simulations de l'atmosphère aux échelles sub-meso (Modeling urban soils for atmospheric simulation at submeso scales). Doctoral thesis, Université de Nantes, $160 \mathrm{pp}$.

Guyot, G., 1997: Climatologie de l'Environnement, de la Plante aux Ecosystèmes. Masson, 525 pp.

Hagishima, A., J. Tanimoto, and K.-I. Narita, 2005: Intercomparisons of experimental convective heat transfer coefficients and mass transfer coefficients of urban surfaces. Bound.-Layer Meteor., 117, 551-576.

Harman, I. N., J. F. Barlow, and S. E. Belcher, 2004: Scalar fluxes from urban street canyons. Part II: Model. Bound.-Layer Meteor., 113, 387-409.

Högström, U., 1996: Review of some basic characteristics of the atmosphere surface layer. Bound.-Layer Meteor., 78, 215246.

Kusaka, H., and F. Kimura, 2004: Thermal effects of urban canyon structure on the nocturnal heat island: Numerical experiment using a mesoscale model coupled with an urban canopy model. J. Appl. Meteor., 43, 1899-1910.

— - H. Kondo, Y. Kikegawa, and F. Kimura, 2001: A simple single-layer urban canopy model for atmospheric models: Comparison with multi-layer and SLAB models. Bound.Layer Meteor., 101, 329-358.

Launiainen, J., 1995: Derivation of the relationship between the Obukhov stability parameter and the bulk Richardson num- ber for flux-profile studies. Bound.-Layer Meteor., 76, 165179.

Lemonsu, A., 2003: Modélisation des processus de surface et de la couche limite en milieu urbain (Modeling of surface processes and boundary layer in urban areas). Doctoral thesis, Université Toulouse III (Paul Sabatier), 490 pp.

_ C. S. B. Grimmond, and V. Masson, 2004: Modeling the surface energy balance of the core of an old mediterranean city: Marseille. J. Appl. Meteor., 43, 312-327.

Long, N., G. Pigeon, P. G. Mestayer, P. Durand, and C. Kergomard, 2003: Correlation between temperature and classification of urban fabric on Marseille during ESCOMPTE. Proc. Fifth Int. Conf. on Urban Climate, Vol. 1, Lodz, Poland, 95-98.

Louka, P., G. Vachon, J.-F. Sini, P. G. Mestayer, and J.-M. Rosant, 2002: Thermal effects on the airflow in a street canyonNantes 99 experimental results and model simulations. Water Air Soil Pollut. Focus, 2, 351-364.

Mahura, A., P. G. Mestayer, S. Dupont, I. Calmet, A. Baklanov, S. Leroyer, and N. Long, 2004: Comparison of short and long-term modelled latent, sensible, and storage heat fluxes employing numerical weather prediction model with and without urbanized modules. Proc. Fourth Annual Meeting of the European Meteorological Society, Vol. 1, Nice, France, European Meteorological Society, 391.

Martilli, A., A. Clappier, and M. W. Rotach, 2002: An urban surface exchange parameterisation for mesoscale models. Bound.-Layer Meteor., 104, 261-304.

Masson, V., 2000: A physically-based scheme for the urban energy budget in atmospheric models. Bound.-Layer Meteor., 98, 357-397.

- C. S. B. Grimmond, and T. R. Oke, 2002: Evaluation of the Town Energy Balance (TEB) scheme with direct measurements from dry districts in two cities. J. Appl. Meteor., 41, 1011-1026.

Mestayer, P. G., and Coauthors, 2005: The urban boundary layer field experiment over Marseille. UBL/CLU-ESCOMPTE: Experimental set-up and first results. Bound.-Layer Meteor., 114, 315-365.

Noilhan, J., and S. Planton, 1989: A simple parametrization of land surface processes for meteorological models. Mon. Wea. Rev., 117, 536-549.

_ and J.-F. Mahfouf, 1996: The ISBA land surface parameterisation scheme. Global Planet. Change, 13, 145-159.

Oke, T. R., R. A. Spronken-Smith, E. Jauregui, and C. S. B. Grimmond, 1999: The energy balance of central Mexico City during the dry season. Atmos. Environ., 33, 3919-3930.

Otte, T. L., A. Lacser, S. Dupont, and J. K. S. Ching, 2004: Implementation of an urban canopy parameterization in a mesoscale meteorological model. J. Appl. Meteor., 43, 1648-1665.

Pigeon, G., A. Lemonsu, V. Masson, and P. Durand, 2003: Seatown interactions over Marseille-Part II: Consequences on atmospheric structure near the surface. Proc. Fifth Int. Conf. on Urban Climatology, Vol. 1, Lodz, Poland, 435-438.

Piringer, M., and S. Joffre, Eds., 2005: The urban surface energy budget and mixing height in European cities: Data, models and challenges for urban meteorology and air quality. Office for Official Publications of the European Communities, Final Report of WG2 COST Action 715, 239 pp.

Pleim, J. E., and A. Xiu, 1995: Development and testing of a surface flux and planetary boundary layer model for application in mesoscale models. J. Appl. Meteor., 34, 16-32.

Recknagel, H., and E. Sprenger, 1995: Données Fondamentales. 
Vol. 1. Manuel Pratique du Génie Climatique. PYC edition, $757 \mathrm{pp}$.

Rotach, M. W., 1995: Profiles of turbulences statistics in and above an urban street canyon. Atmos. Environ., 29, 14731486.

1999: On the influence of the urban roughness sublayer on turbulence and dispersion. Atmos. Environ., 33, 4001-4008.

Rowley, F. B., A. B. Algren, and J. L. Blackshaw, 1930: Surface conductances as affected by air velocity, temperature and character of surface. ASHRAE Trans., 36, 429-446.

Schmid, H. P., and T.R. Oke, 1990: A model to estimate the source area contributing to turbulent exchange in the surface layer aver patchy terrain. Quart. J. Roy. Meteor. Soc., 116, 965-988.

Voogt, J. A., and C. S. B. Grimmond, 2000: Modeling surface sensible heat flux using surface radiative temperatures in a simple urban area. J. Appl. Meteor., 39, 1679-1699.

Willmott, C. J., 1982: Some comments on the evaluation of model performance. Bull. Amer. Meteor. Soc., 63, 1309-1313.

Zilitinkevich, S. S., 1995: Non-local turbulent transport: pollution dispersion aspects of coherent structure of convective flows. Air Pollution Theory and Simulation, H. Power, N. Moussiopoulos, and C. A. Brebbia, Eds., Vol. 1, Air Pollution III, Computational Mechanics Publications, 53-60. 